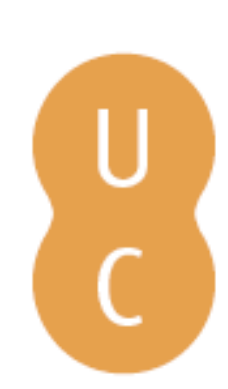

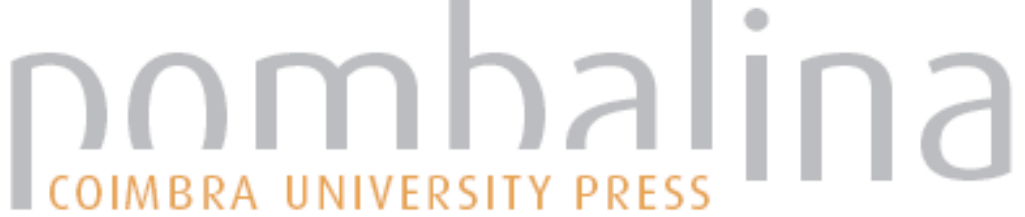

\section{Formação de verbos}

Autor(es): $\quad$ Pereira, Rui A.

Publicado por: Imprensa da Universidade de Coimbra

URL

persistente: URI:http://hdl.handle.net/10316.2/38916

DOI: $\quad$ DOI:http://dx.doi.org/10.14195/978-989-26-0864-8_4

Accessed : $\quad$ 26-Apr-2023 16:20:18

A navegação consulta e descarregamento dos títulos inseridos nas Bibliotecas Digitais UC Digitalis, UC Pombalina e UC Impactum, pressupõem a aceitação plena e sem reservas dos Termos e Condições de Uso destas Bibliotecas Digitais, disponíveis em https://digitalis.uc.pt/pt-pt/termos.

Conforme exposto nos referidos Termos e Condições de Uso, o descarregamento de títulos de acesso restrito requer uma licença válida de autorização devendo o utilizador aceder ao(s) documento(s) a partir de um endereço de IP da instituição detentora da supramencionada licença.

Ao utilizador é apenas permitido o descarregamento para uso pessoal, pelo que o emprego do(s) título(s) descarregado(s) para outro fim, designadamente comercial, carece de autorização do respetivo autor ou editor da obra.

Na medida em que todas as obras da UC Digitalis se encontram protegidas pelo Código do Direito de Autor e Direitos Conexos e demais legislação aplicável, toda a cópia, parcial ou total, deste documento, nos casos em que é legalmente admitida, deverá conter ou fazer-se acompanhar por este aviso.

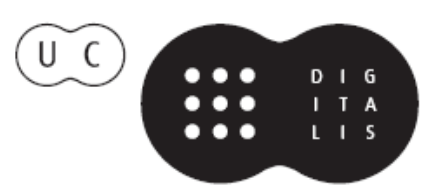




\section{GRAMÁTICA \\ DERIVACIONAL \\ DO PORTUGUÊS}

GRAÇA RIO-TORTO

ALEXANDRA SOARES RODRIGUES

ISABEL PEREIRA

RUI PEREIRA

SÍLVIA RIBEIRO

2. ${ }^{a}$ EDIÇÃO

IMPRENSA DA UNIVERSIDADE DE COIMBRA COIMBRA UNIVERSITY PRESS 


\section{CAPÍTULO 4. FORMAÇÃO DE VERBOS}

Rui A. Pereira

Neste capítulo descreve-se a formação de verbos. Após uma secção introdutória (4.1.), consagrada aos processos de formação de verbos, caraterizam-se em 4.2. as propriedades das bases e em 4.3. as dos afixos e dos produtos heterocategoriais; a secção 4.4. é consagrada à formação isocategorial de verbos.

\subsection{Processos de formação de verbos}

$\mathrm{Na}$ formação de verbos em português, os processos derivacionais podem ser classificados em função de dois tipos de critérios de análise: (i) o critério formal, que tem em conta o contraste formal entre base e derivado; e (ii) o critério categorial, que considera a categoria gramatical das bases e das respetivas palavras derivadas.

É com base na avaliação formal do par base/derivado que se fala em afixação (prefixação, sufixação, circunfixação ou, tradicionalmente, parassíntese) e em conversão.

Tomando a forma da base, i.e., a forma do lexema a partir do qual se produz uma nova palavra, como ponto de partida na descrição dos processos morfológicos, podem-se distinguir dois tipos gerais de processos formadores de verbos em português: aditivos e não aditivos. Através de processos aditivos (principalmente afixais), a 
base é acrescentada de elementos externos a ela, pelo que o radical do verbo gerado é formalmente mais extenso que a base (cf. [clar] > [aclar $]$ ar $;[$ hospital $]>[$ hospitaliz $]$ ar $;[$ trist $]>$ [entristec $]$ er $)$. Nos casos de conversão, a base vê alterado o seu valor categorial e semântico, mas não a forma do seu radical (cf. $[l i x]_{\operatorname{RadN}}>[l i x]_{\text {Radv }}$ ar).

Em termos categoriais, a formação de verbos pode tomar como bases várias classes de radicais, nomeadamente nominais, adjetivais e verbais. É com base nesta informação que falaremos em verbalização denominal, deadjetival e deverbal (cf. cap. 4: 2.1). Os processos derivacionais são isocategoriais quando não alteram a classe gramatical da base (saltar/saltitar; cuspir/cuspinhar), e heterocategoriais se formam verbos a partir de outras classes de palavras (rem- RadN $>$ remar $_{\mathrm{V}} ;$ sinal $_{\mathrm{RadN}}>$ sinalizar $_{\mathrm{V}}$; escur- RadA $_{\text {incurecer }}$ ).

São, pois, de natureza aditiva e conversiva as operações que sustentam os principais padrões de formação de verbos em português 52. São residuais os verbos formados com base em compostos: além de curto-circuitar 'provocar um curto circuito', mata-bichar, comum no português de Moçambique, microfilmar 'fazer um microfilme', vangloriar-se, regista-se também malditar-se, este criado por Mia Couto, em Cada homem é uma raça (1990).

O quadro seguinte sintetiza a distribuição dos processos de formação de verbos em português em função dos critérios observados:

\begin{tabular}{|l|l|l|}
\hline Processos & Derivação isocategorial & Derivação heterocategorial \\
\hline prefixação & $\begin{array}{l}\text { antepor } \\
\text { desdizer } \\
\text { preestabelecer } \\
\text { recolocar }\end{array}$ & $\begin{array}{l}\text { abrandar } \\
\text { ensacar } \\
\text { esvaziar }\end{array}$ \\
\hline sufixação & $\begin{array}{l}\text { mordiscar } \\
\text { saltitar }\end{array}$ & $\begin{array}{l}\text { exemplificar } \\
\text { favorecer } \\
\text { pentear } \\
\text { tranquilizar }\end{array}$ \\
\hline
\end{tabular}

52 Para uma análise circunstanciada dos vários processos de formação de verbos em português, ver Rio-Torto (1998; 2004) e Pereira (2007). 


\begin{tabular}{|l|l|l|}
\hline circunfixação & adormecer & $\begin{array}{l}\text { anoitecer } \\
\text { atemorizar } \\
\text { empobrecer } \\
\text { esquartejar }\end{array}$ \\
\hline Conversão & - & $\begin{array}{l}\text { alegrar } \\
\text { lixar } \\
\text { martelar }\end{array}$ \\
\hline
\end{tabular}

Quadro IV.1. Processos de formação de verbos

\subsubsection{Processos afixais}

Em português, os afixos usados na formação de verbos são de tipo não intrusivo, ou seja, posicionam-se nas margens esquerda (e.g. $\left.a_{-}^{-}, e n-, e s-\right)$ ou direita $\left(-e-,-e j-,-e(s) c_{-},-i z-,-i c-,-i t-\right)$ da base lexical a que se juntam. Estes afixos são breves, raramente ultrapassando a extensão de uma sílaba com uma sequência VC. Em função da posição dos afixos em relação à base, definem-se três classes de afixação:

(i) a prefixação (abrandar, antepor, descolar, ensacar, esvaziar, predizer, recolocar (cf. 4.3.3.2.));

(ii) a sufixação (exemplificar, mordiscar, pentear, saltitar, tranquilizar (cf. 4.3.3.3.));

(iii) a circunfixação (anoitecer, atemorizar, empobrecer, esclarecer (cf. 4.3.3.4.)).

Os afixos são unidades sígnicas dotadas de significação, que associam um significado a um significante, não se limitando a sua identidade à de marcadores sintáticos ou à de expoentes dos processos derivacionais. A comparação do significado de verbos formados a partir da mesma base (e.g. aclarar, clarear, clarificar, esclarecer) comprova que as unidades afixais têm um significado próprio que 
permite a diferenciação dos produtos derivados. Por outras palavras, a instanciação de um determinado afixo não só adiciona material fonológico à base, como pode alterar a sua informação categorial, e contribui composicionalmente para o valor semântico do produto derivacional; o significado do verbo derivado decorre da confluência da instrução semântica do afixo e do significado da base. Para além disso, cada afixo institui um conjunto de condições que determinam o(s) tipo(s) de bases a que se podem ou não acoplar.

\subsubsection{Um processo não afixal: a conversão}

Em português também é possível a formação de verbos sem o uso de afixos. Em casos como [árbitr $]_{\mathrm{RadN}} O>[$ arbitr $]$ ar, $[\text { alegr }]_{\mathrm{RAdA}}$ $e>[$ alegr $]$ ar ou [pincel $]_{\mathrm{RadN}}>[$ pincel $]$ ar, a base não sofre nenhuma modificação em termos formais. A esta operação que altera a categoria gramatical e semântica da base sem lhe alterar a aparência formal do seu radical dá-se o nome de conversão (cf. 1.6.3).

Em português, os verbos e os nomes/adjetivos têm uma estrutura morfológica notoriamente diferente (cf. alegre: alegrar; betume: betumar; $\operatorname{suj}(o / a)$ : sujar; vacina: vacinar), o que não acontece em outras línguas, como o inglês (cf. Don 1993, Don et al. 2000; por exemplo (a)drink $k_{\mathrm{N}}$, (to) drink $k_{\mathrm{V}}$ ). Todavia, a conversão opera com radicais e por isso base e derivado têm a mesma aparência formal (cf. [alegr]e: [alegr]ar; [perfum]e: [perfum]ar; [vacin]a: [vacin]ar). Os casos de alomorfia da base são descritos em 4.2.3.

Uma vez que a conversão não faz uso de afixos, a direcionalidade do processo derivacional pode ser difícil de identificar, dada a ausência de marcas explícitas que estabeleçam a relação entre bases e derivados. No caso da conversão, a configuração formal das unidades derivacionalmente relacionadas não nos permite decidir a priori qual a base e qual o derivado. Observemos os seguintes exemplos: 
(1) a. árbitro / arbitrar

b. regimento / regimentar

c. embarque / embarcar

d. lixa / lixar

e. compra / comprar

Como determinar se é o verbo derivado a partir do nome, ou se é o nome que tem por base o verbo? A direção da derivação pode ser estabelecida com base na aplicação conjunta de critérios morfofonológicos e sintático-semânticos (Rodrigues 2001, 2002). Assim, num par de palavras Nome/Verbo com um radical idêntico, o nome será derivado se:

(i) contiver afixação geradora de verbos,

(ii) ostentar significações que refletem a herança verbal.

O nome será derivante se apresentar acentuação marcada como não autóctone.

Aplicando estes critérios aos exemplos apresentados, podemos verificar o seguinte: árbitro (1a) possui uma acentuação [+ marcada], pois o acento recai sobre uma sílaba anterior à que inclui a última vogal do radical; regimento (1b) integra um sufixo deverbal (-ment(o)); embarque (1c) integra um prefixo (em-) que forma verbos denominais; dos nomes de (1d) e (1e), apenas compra ('ato ou ação de comprar') possui um significado que reflete a sua herança verbal. Conclui-se, então, que em (1a, b, d) a direção de derivação é $\mathrm{N} \rightarrow \mathrm{V}$, ou seja, os radicais de árbitro, regimento e lixa são as bases nominais de que se formam os verbos derivados arbitrar, regimentar e lixar; em (1c, e) a direção da derivação é $\mathrm{V} \rightarrow \mathrm{N}$, ou seja, embarque e compra são nomes deverbais (cf. cap. 2: 2.4.3.1.).

Em pares como engano/enganar, conversa/conversar, ainda que não ocorram lexemas com acentuação não autóctone, nem afixações 
que revelem a origem básica ou derivada do verbo ou do nome, os nomes ostentam estrutura argumental, para além de eventiva, que aponta a sua origem deverbal.

\subsection{Bases}

\subsubsection{Classes léxico-sintáticas}

Os verbos da língua portuguesa podem ser formados a partir de três classes lexicais: nomes, adjetivos e verbos. Encontram-se esporadicamente verbos formados a partir de outras classes de bases: pronomes (atuar 'tratar por tu', envosar), advérbios (acercar, adentrar), onomatopeias (cacarejar, enxotar, tiquetaquear). Trata-se de situações raras e excecionais, que atualmente não representam padrões regulares de formação.

Assim, a formação de verbos assenta num de três tipos de relações derivacionais:

\begin{tabular}{|c|c|c|c|}
\hline Relação derivacional & Base & & Produto \\
\hline a. $A \rightarrow$ V: verbalização deadjetival & $\begin{array}{l}\text { claro } \\
\text { branco } \\
\text { escuro } \\
\text { sólido } \\
\text { vulgar }\end{array}$ & $\begin{array}{l}\rightarrow \\
\rightarrow \\
\rightarrow \\
\rightarrow \\
\rightarrow\end{array}$ & $\begin{array}{l}\text { aclarar } \\
\text { branquejar } \\
\text { escurecer } \\
\text { solidificar } \\
\text { vulgarizar }\end{array}$ \\
\hline b. $\mathbf{N} \rightarrow \mathbf{V}$ : verbalização denominal & $\begin{array}{l}\text { susto } \\
\text { saco } \\
\text { farrapo } \\
\text { dano } \\
\text { temor }\end{array}$ & $\begin{array}{l}\rightarrow \\
\rightarrow \\
\rightarrow \\
\rightarrow \\
\rightarrow\end{array}$ & $\begin{array}{l}\text { assustar } \\
\text { ensacar } \\
\text { esfarrapar } \\
\text { danificar } \\
\text { atemorizar }\end{array}$ \\
\hline c. $\mathbf{V} \rightarrow \mathbf{V}:$ verbalização deverbal & $\begin{array}{l}\text { saltar } \\
\text { morder } \\
\text { lembrar } \\
\text { coser }\end{array}$ & $\begin{array}{l}\rightarrow \\
\rightarrow \\
\rightarrow \\
\rightarrow\end{array}$ & $\begin{array}{l}\text { saltitar } \\
\text { mordiscar } \\
\text { relembrar } \\
\text { descoser }\end{array}$ \\
\hline
\end{tabular}

Quadro IV.2. Relações derivacionais instanciadas na formação de verbos 
Os afixos utilizados em processos de verbalização heterocategorial (cf. Quadro IV.2: a. e b.) intervêm apenas na formação de verbos, mas os afixos ativados na verbalização deverbal (cf. Quadro IV.2: c.) podem selecionar bases de diversas classes e ocorrer em processos de nominalização e/ou de adjetivalização. O quadro seguinte apresenta alguns exemplos:

\begin{tabular}{|l|l|l|l|}
\hline Afixo & Base nominal & Base adjetival & Base verbal \\
\hline -inh- & carrinho, mesinha & bonitinho, velhinho & cuspinhar \\
\hline -it- & janelita & tolito & dormitar, saltitar \\
\hline -ic- & abanico, burrico & grandico, tolico (PE reg.) & tossicar \\
\hline -isc- & chuvisco & gravisco, vivisco & mordiscar \\
\hline -ot- & casota, ilbota & baixote, pequenote & bailotar $($ PE reg.) \\
\hline -ol- & sacola & bebedola(s) & cantarolar \\
\hline ante- & antecâmara & antepenúltimo & antever \\
\hline des- & desamor & descontente & desconfiar \\
\hline re- & recanto, renome & revelho & recontar \\
\hline
\end{tabular}

Quadro IV.3. Sufixos e prefixos policategoriais

\subsubsection{Classes morfológicas}

Os verbos, formados isocategorialmente ou heterocategorialmente, nunca têm por base um tema. Essa impossibilidade estrutural tem uma motivação fonético-fonológica: como os sufixos de formação de verbos começam por segmento vocálico (-e-, -ej-, -ific-, -iz-), a sua adjunção a bases terminadas em vogal criaria sequências hiáticas, que a língua tende a evitar.

A construção de verbos (cf. Quadro IV.4.) seleciona apenas dois tipos morfológicos de bases:

(i) radical [-autónomo], como em a[dorm]ecer, [clar]ear, [celebr] izar, [exempl]ificar, [salt]itar, [toss]icar, e 
(ii) radical-palavra, como em a[terror]izar, [cantar]olar, [favor]ecer, [fertil] izar, [gas]ificar, [hospital]izar, [mar]ejar, [pastor]ear, [saltar]icar.

Em [cantar] olar ou [saltar]icar é o radical simples, que coincide com a configuração do infinitivo do verbo, que é tomado como base: daí a denominação de radical-palavra, em resultado dessa reanálise. Nos casos de derivação em que a base é preenchida por uma palavra há em PE marcas prosódicas disso; ora, o que acontece nos verbos em análise é justamente o contrário: a elevação das vogais da base, em cotexto derivacional (cf. a[terror]izar, [favor]ecer, [fertil]izar, [gas]ificar, [mar]ejar, [pastor]ear, [saltar]icar) aponta para uma regularização destas formas com os demais paradigmas de formação sufixal, quando as bases são preenchidas com radicais.

Quando o radical de base termina em vogal acentuada, forma-se em alguns casos um hiato (pé: apear), enquanto noutros a ligação entre base e o sufixo é auxiliada por uma consoante de ligação ou interfixo (cf. 1.6.1.4) (pá: padejar), que assim evita a criação de um hiato.

No Quadro IV.4 apresentam-se as configurações morfológicas das bases selecionadas pelos processos de formação de verbos.

\begin{tabular}{|c|c|c|}
\hline Classe morfológica & Derivação isocategorial & Derivação heterocategorial \\
\hline $\begin{array}{l}\text { 1. Base: Radical } \\
\text { [-autónomo] }\end{array}$ & $\begin{array}{l}{[\text { [salt }] \text { it }(\text { ar })} \\
\mathrm{a}[\text { dorm }] e c(\mathrm{er})\end{array}$ & $\begin{array}{l}\text { [exempl]ific(ar) } \\
\text { [escur]ec(er) }\end{array}$ \\
\hline 2. Base: Radical-palavra & [saltar]ic(ar) [cantar]ol(ar) & [favor]ec(er) a[terror]iz(ar) \\
\hline
\end{tabular}

Quadro IV.4. Classes morfológicas de bases selecionadas pelos processos verbalizadores

\subsubsection{Alomorfia}

Em muitos casos, a configuração da base não se altera por via do processo derivacional: [clar]o/a: a[clar]ar; [escur]o/a: [escur] ecer; [verd]e: [verd]ejar). 
Mas por vezes a base nominal ou adjetival apresenta em contexto derivacional uma variante formal ou alomórfica que, não raro, reflete:

(i) a sua origem latina (cf. [arbor]izar, a[lun]ar, [carbon]izar, [dulc]ificar) ou

(ii) a sua configuração em fases pretéritas da língua (cf. afrechar < port. ant. frecha 'flecha'; emperlar < port. ant. perla 'pérola'; endiabrar < port. ant. diabro 'diabo').

Nestes casos, a base lexical ocorre com uma forma diferente (por vezes apenas parcialmente) da que tem enquanto palavra autónoma: às palavras árvore, carvão, doce, lua, correspondem as formas presas e eruditas arbor-, carbon-, dulc- e lun-. Na derivação (arborizar, alunar, carbonizar, dulcificar), como na composição (carbonífero, dulcímetro), são muitas vezes estas formas alomórficas as utilizadas.

Algumas variantes formais das bases podem ser explicadas à luz de processos fonológicos ainda ativos na língua portuguesa. Assim acontece em capitão: capitanear, Japão: japonizar, paz: pacificar. Noutros casos, a base lexical adota uma variante formal alternativa, normalmente de origem latina ou grega: corpo: corporificar; lágrima: lacrimejar; problema: problematizar; sintese: sintetizar. Estas formas de base, marcadas com o traço [- autónomo] e/ou [+ erudito], colocam problemas de de(s)codificação do verbo derivado, uma vez que são do conhecimento apenas de um grupo limitado de falantes, mais especificamente, os que aprenderam explicitamente a relação existente entre estas formas de base e as variantes [- eruditas] das unidades lexicais em causa.

As variantes formais ou alomórficas das unidades lexicais têm na sincronia atual propriedades formais e funcionais distintas, coexistindo geralmente numa relação de complementaridade (Pereira 2005). As variantes eruditas são formas presas que só se manifestam 
em contexto derivacional (corp-(or)-: corporificar); ); pelo contrário, as variantes [- eruditas], para além de poderem funcionar como formas derivantes de palavras complexas (corp-: encorpar; corpinho), podem ocorrer como radicais de palavras simples $(\operatorname{corpo})$.

\subsection{Formação heterocategorial de verbos}

A formação heterocategorial de verbos processa-se a partir de bases de categoria nominal ou adjetival. Porque são semelhantes os processos derivacionais utilizados em ambos os casos, estas duas classes de verbos derivados serão analisadas em conjunto.

\subsubsection{Morfologia dos verbos denominais e deadjetivais}

São quatro os tipos de esquemas configuracionais dos verbos denominais e deadjetivais formados em português (cf. Quadro IV.5.). Toma-se como referência a forma de Infinitivo dos verbos, por ser a forma de citação destes; mas a VT e a marca de Infinitivo do verbo não são constituintes derivacionais, pelo que se apresentam entre (...).

\begin{tabular}{|c|c|c|}
\hline & esquema configuracional & exemplos \\
\hline I. & $\begin{array}{l}{\left[[\mathrm{b} a s e]_{\mathrm{RadN} / \mathrm{A}}\right]_{\mathrm{RadV}}(\mathrm{VT}, \text { morfema de }} \\
\text { Infinitivo) }\end{array}$ & $\begin{array}{l}\text { ancorar, azedar, lixar, murar, } \\
\text { martelar, perfumar }\end{array}$ \\
\hline II. & $\begin{array}{l}{\left[\text { Prefixo }[\mathrm{base}]_{\mathrm{RadN} / \mathrm{A}}\right]_{\mathrm{RadV}}(\mathrm{VT}, \text { morfema }} \\
\text { de Infinitivo) }\end{array}$ & $\begin{array}{l}\text { acalorar, aclarar, encaixar, entubar, } \\
\text { esfriar, esvaziar }\end{array}$ \\
\hline III. & $\begin{array}{l}{\left[[\text { base }]_{\text {RadN/A }} \text { sufixo }\right]_{\text {Radv }} \text { (VT, morfema de }} \\
\text { Infinitivo) }\end{array}$ & $\begin{array}{l}\text { suavizar, clarificar, facilitar, } \\
\text { favorecer, coxear, gotejar }\end{array}$ \\
\hline IV. & $\begin{array}{l}\text { [Constituinte de circunfixo }[\text { base }]_{\mathrm{RadN} / \mathrm{A}} \\
\text { constituinte de circunfixo }]_{\mathrm{RadV}}(\mathrm{VT}, \\
\text { morfema de Infinitivo) }\end{array}$ & $\begin{array}{l}\text { atemorizar, encolerizar, apodrecer, } \\
\text { envelhecer, esfaquear, espernear }\end{array}$ \\
\hline
\end{tabular}

Quadro IV.5. Esquemas configuracionais dos verbos denominais e deadjetivais 
A determinação do processo ativado em cada um dos casos implica uma tomada de posição sobre a natureza e estatuto dos constituintes que se localizam à direita e à esquerda dos radicais destes verbos. Disso se ocupam as secções 4.3.1.1. e 4.3.1.2.

\subsubsection{Vogal Temática}

Ao constituinte temático dos verbos, tradicionalmente conhecido como Vogal Temática (VT), tem sido atribuído valor derivacional, descrevendo-se os verbos de tipo azedar, murar, martelar, perfumar como derivados pelo «sufixo verbal explícito -ar» (Sandman 1989: 72).

Ora, a Vogal Temática é um constituinte consubstancial a todas as formas verbais regulares e tem como principal função conformar o Tema do verbo, integrando-o num paradigma conjugacional (Cunha \& Cintra 1984: 102; Rio-Torto 1998b, 2004) ${ }^{53}$. Na palavra derivada, após ativação do processo derivacional, o radical formado ou convertido é completado por uma vogal de tema, colocando-o em condições de sofrer a flexão verbal. Não se trata, portanto, nem de um constituinte flexional nem de um sufixo derivacional. A sua função primordial é a de constituinte temático ou integrador paradigmático, pelo que o acréscimo de - $a$ - (ou - $e$-, quando precedido de -ec- ou -esc-) decorre do facto de os verbos terem vogal temática em português.

A consideração da VT como formatador morfológico da base, primitiva ou derivada, implica que a sua ativação seja exterior ao processo derivacional. Vários argumentos de natureza morfológica suportam esta conceção:

53 Tenha-se em conta que, na adaptação de empréstimos à estrutura do português, os novos verbos são formatados morfologicamente com a VT -a-: checar, clicar, flirtar, snifar, sprintar, stressar. 
(i) os verbos não derivados (e.g. chegar, dormir, morrer) também são portadores de VT, pelo que não se pode dizer que esta sinaliza necessariamente um processo derivacional;

(ii) na formação de verbos deverbais (cf. $\operatorname{com}[e] r>\operatorname{comisc}[a] r ; \operatorname{dorm}[i]$ $r>\operatorname{dormit}[a] r ;$ cusp $[i] r>$ cuspinb $[a] r)$, apesar de a base estar morfologicamente especificada por uma VT, o sufixo derivacional ativado (-it-, -isc-, -inh-) determina a atribuição de uma outra VT ao produto derivado, pelo que, não fazendo a VT parte do sufixo, só pode ser atribuída em outro nível de estruturação.

Em suma, considera-se que a VT não integra o produto derivacionalmente construído, mas é-lhe associada posteriormente no processo de formatação temática, pelo que o produto resultante do processo genolexical terá a configuração não de um tema, mas de um radical verbal. Se nos verbos em que estão presentes operadores derivacionais como -e-, -ec-, -ej-, -esc-, -iz-, -ific-, nos podemos dispensar de atribuir à VT uma função derivacional, o mesmo acontece também quando estes estão ausentes.

Os verbos afixados distribuem-se por duas classes temáticas (- $a$-, -e-), sendo a especificação da VT da responsabilidade dos operadores sufixais envolvidos: $-e_{-},-e j-,-e n t-,-i t-,-i c-,-i z-,-i f i c-$ impõem a ocorrência de VT - $a$-, enquanto $-e(s) c$ - apenas admite VT $-e$ -

É a VT - $a$ - que, na ausência de qualquer sufixo, é ativada por defeito. A formação de verbos com VT - $i$ - não é atualmente produtiva em português, encontrando-se apenas num conjunto residual de verbos bem determinado numericamente (e.g. colorir, cuspir, florir).

\subsubsection{Prefixos}

É controverso o papel desempenhado pelos prefixos no processo derivacional, quer pela falta de consenso relativamente aos seus 
poderes de categorização, quer pela sua inclusão ora no domínio da afixação, ora no da composição.

No caso dos constituintes $a$-, en- e es- que intervêm na formação de verbos, consideramo-los como afixos derivacionais. A função sintático-semântica desempenhada por estes prefixos é similar à realizada por alguns sufixos derivacionais (Pereira 2000). Tal como alguns sufixos, os prefixos $a$-, en- e es- não só participam na construção do significado do verbo derivado, como o produto em que ocorrem tem uma categoria sintática diferente da da base a que se ligam: clar $_{\text {-RadA }}>$ aclarar $_{\mathrm{V}} ; s a$-RadN $_{\text {R }}>$ ensacar $_{\mathrm{V}} ;$ vazi-RadA $_{\text {-R }}>$ esvaziar $_{\mathrm{V}}$.

Em alternativa, pode considerar-se que estamos perante um caso de parassíntese (cf. Basílio \& Martins 1996). Mas se em circunstância alguma a VT funciona como sufixo derivacional, porque haveria de ter esse estatuto neste caso?

Por norma, os prefixos não determinam as categorias morfológica, sintática e morfo-semântica das palavras em que ocorrem; mas os prefixos $a$-, $e n$ - e $e s-$, na ausência de constituintes sufixais à direita da base que o façam, induzem uma recategorização do novo radical, face ao da base a que se juntam. Esta proposta é sustentada por vários argumentos de natureza morfo-semântica: a semântica manifestada pelos verbos derivados deixa transparecer uma relação semântico-categorial com uma base nominal ou adjetival (cf. aclarar: 'tornar claro'; engarrafar: 'pôr em garrafa'; esladroar: 'tirar/ extrair os ladrões'), e não com alguma base verbal não prefixada, atestada ou possível, e na maior parte dos casos inexistente (v.g. *clarar, "garrafar, *ladroar).

A coexistência, ainda que rara, de verbos prefixados e não prefixados com uma mesma base, como aparafusar/parafusar, embaralhar/baralhar, emoldurar/moldurar, e em que parafusar e moldurar são os menos comuns em PE, não permite concluir linearmente que os verbos não prefixados sejam as bases derivantes dos verbos prefixados. Acresce que estes apresentam, muitas 
vezes, valores semântico-aspetuais, especializações referenciais ou realizações argumentais que os distinguem dos não prefixados (cf. forrar/aforrar, guardar/aguardar, listar/alistar, planar/aplanar, segurar/assegurar, testar/atestar) ou dos prefixados com operadores diferentes (cf. enterrar/ aterrar, enfarinhar/esfarinhar) ${ }^{54}$. Nada impede, pois, que num mesmo paradigma de formação de palavras possam atuar diversas operações morfológicas concorrenciais, encarregando-se a língua de institucionalizar aquela(s) que é/são necessária(s) e semântica e/ou referencialmente distinta(s).

\subsubsection{Estrutura semântica e argumental dos verbos heterocategoriais e dos seus constituintes}

Os verbos deadjetivais e denominais expressam, na sua globalidade, uma mudança de estado-de-coisas, que pode envolver o incremento ou transferência de propriedades, estados ou entidades. Essa mudança de estado-de-coisas pode ser concebida e/ou expressa como interna ou externamente causada, sendo neste último caso manifesta a intervenção de um sujeito causativo. A expressão da 'causa' ou 'agente causador' é muitas vezes opcional, podendo os verbos derivados expressar, alternativamente ou não, eventos não causativos. Esse fenómeno é tradicionalmente conhecido no domínio da semântica e da sintaxe como "alternância causativo/incoativo» ou simplesmente como "alternância causativa".

A quase totalidade dos verbos heterocategorialmente derivados distribui-se por seis classes semânticas (Pereira 2007, 2009), de

$54 \mathrm{Na}$ linguagem dos falantes não instruídos do PE continua a usar-se um a- protético em verbos como (a)baixar, (a)costumar, (a)juntar, (a)levantar, (a) mandar, (a)mostrar, (a)semear, (a)sentar, sendo que, nestes casos, a presença de $a$ - não assegura contraste semântico, como em aguardar vs. guardar. Também não é linear que se trate de um prefixo, neste caso esvaziado de conteúdo semântico, ainda que por reanálise da preposição latina que está na sua origem. 
acordo com o padrão léxico-conceptual que denotam ( $\mathrm{Xb}$ representa a base lexical):

\begin{tabular}{|c|c|c|}
\hline $\begin{array}{l}\text { Classe } \\
\text { semântica }\end{array}$ & Paráfrase & Exemplos \\
\hline \multirow{3}{*}{ resultativo } & 'tornar Xb' & alisar, atualizar, enfraquecer, falsificar \\
\hline & 'transformar em Xb' & $\begin{array}{l}\text { acardumar, aveludar, caramelizar, } \\
\text { coisificar }\end{array}$ \\
\hline & 'causar Xb' & aterrorizar, enfurecer \\
\hline \multirow{2}{*}{ locativo } & 'pôr em Xb' & engarrafar, hospitalizar, hastear \\
\hline & 'tirar de Xb' & espipar, esventrar \\
\hline \multirow{2}{*}{ ornativo } & 'prover com Xb' & atapetar, arborizar, encerar, gradear \\
\hline & 'tirar Xb de' & esladroar, espulgar \\
\hline instrumental & 'ferir/afetar com Xb' & apunhalar, esporear, varejar \\
\hline performativo & 'fazer/realizar/produzir Xb' & festejar, frutificar, guerrear \\
\hline \multirow{2}{*}{ modal } & 'agir como/de forma Xb' & gaguejar, serpentear \\
\hline & 'exercer as funções de Xb' & capitanear, fiscalizar, pastorejar \\
\hline
\end{tabular}

Quadro IV.6. Classes semânticas de verbos heterocategoriais em português

Nenhum esquema argumental está vedado aos diversos processos derivacionais em jogo, podendo-se encontrar verbos derivados com (i) zero argumentos, como nevar, trovejar, (ii) monádicos, como cicatrizar, enviuvar, espernear, florescer, frutificar, (iii) diádicos, como apedrejar, atapetar, fertilizar, e (iv) triádicos, como aprisionar, enterrar.

Não obstante a diversidade de esquemas possíveis, os verbos derivados apresentam de uma maneira geral uma estrutura argumental diádica ou biargumental (ㅁ, y) (e.g. apimentar, ensacar, esclarecer, esquentar, favorecer, martirizar, simplificar), que admite duas variantes de realização sintática: uma transitiva e uma inacusativa. Por força da mudança de estado-de-coisas instanciada e/ou da perspetivação que o falante lhe imprime, os processos de formação de verbos podem fazer emergir o argumento externo causador, ou prescindir dele. São muito frequentes os casos em 
que o verbo derivado pode ser realizado transitivamente com valor causativo ou alternativamente como inacusativo, expressando um significado incoativo (o barulho ensurdeceu-o/ele ensurdeceu; a máquina secou a roupa/a roupa secou (ao sol); o cão assustou o José/o José assustou-se).

Em algumas situações, o português aproveita a diversidade de processos derivativos para marcar uma oposição entre verbos transitivos e verbos intransitivos, como sucede nos seguintes pares de verbos formados com base no mesmo radical nominal ou adjetival que têm esquemas de realização sintática diferentes: aplanar $r_{\text {transit. }}$ vs. planar $_{\text {intransit.; }}$ espreguiçar $r_{\text {transit }}$ vs. preguiçar $_{\text {intransit. }}$.

\subsubsection{Condições de aplicação e produtos}

Os processos de formação de palavras não são totalmente livres na sua possibilidade de formar novas palavras complexas. Mesmo os processos ou afixos mais produtivos parecem estar sujeitos a certas condições estruturais de aplicação e até a influências extralinguísticas (Pereira 2004). A não ativação de um determinado processo ou afixo numa situação concreta pode decorrer das propriedades fonológicas, morfológicas ou semântico-aspetuais evidenciadas pelas bases lexicais (cf. 1.5.3).

A formação de verbos recorre preferencialmente, mas não exclusivamente, a adjetivos que descrevem 'propriedades de fase ou de estádio', i.e., adjetivos que descrevem propriedades transitórias ou ocasionais de entidades que podem ser mudadas por uma causa, como as suas caraterísticas físicas, a cor ou a temperatura (cf. aclarar, amadurecer, branquear, encurtar, esquentar, esvaziar, purificar). Em contraste, os adjetivos que designam 'propriedades de indivíduo', propriedades essenciais de um dado referente, tipicamente não adquiríveis como um resultado de uma causa, não 
constituem bases ideais para a formação de verbos de mudança de estado (*aferozar, *enferocecer, *inteligentear, *inteligentificar, *intelingentizar).

Alguns predicados de indivíduo (cf. católico) podem servir de base a processos de verbalização. Neste caso há lugar a uma alteração radical do estado de coisas, pelo que os produtos verbais significam 'tornar-se Ab' (catolicizar) e não 'tornar-se mais Ab', como acontece quando o verbo é construído sobre um predicado de fase ou de estádio (avermelhar, esfriar, encurtar, esclarecer).

Ao nível da formação denominal, existem também alguns tipos de bases nominais (algumas delas derivadas) que não são suscetíveis de funcionar como base derivacional: (a) nomes de evento denominais em -ad(a) (cf. *cabeçadar, *cacetadizar, *caneladear, *acacetadar, *cotoveladecer), (b) nomes agentivos deverbais em -dor (cf. *ajogadorar, *arrumadorecer, *fumadorizar, *varredorar), ou (c) nomes deadjetivais em -idad(e) (*amabilidadar, *credibilidadizar, *perigosidadecer). Os nomes próprios revelam um funcionamento particular. Embora se encontrem atestadas formações como agongorar, galvanizar, pasteurizar, derivadas dos radicais de Gôngora, Galvani e Pasteur, a base nominal não designa propriamente o indivíduo referido pelo nome próprio, mas remete metonimicamente para alguma(s) propriedade(s) da sua obra, ideias ou teorias. Nestes casos, as bases são recategorizadas como nomes comuns.

A escolha de determinado afixo (fiscalizar, mas *fiscalecer) ou processo (martelar, mas *martelizar) parece depender muitas vezes das (im)possibilidades combinatórias que cada um destes institui com as respetivas bases e do contributo específico e distintivo de cada um para a configuração final dos produtos verbais. Alguns processos de formação de verbos apresentam (in)compatibilidades entre os afixos usados e as propriedades formais e/ou semânticas das bases a que se conectam, nomeadamente no que diz respeito à presença de alguma(s) classe(s) de afixos na sua estrutura in- 
terna. Mais do que restrições claramente diferenciadoras, existem condições preferenciais de ativação que fazem variar o domínio de aplicação dos diversos processos, restringindo assim a sua concorrência (Pereira 2004, 2013).

Nas secções seguintes apresentam-se as condições de ativação dos recursos genolexicais e as especificidades dos verbos derivados através dos diversos processos de formação heterocategorial no português europeu: conversão (4.3.3.1.) e afixação. No âmbito dos verbos formados por afixação incluem-se os que envolvem prefixação (4.3.3.2.), sufixação (4.3.3.3.) e circunfixação (4.3.3.4.).

\subsubsection{Verbos formados por conversão}

Quando formados por conversão de radicais, os verbos não apresentam qualquer afixo derivacional (prefixo, sufixo ou circunfixo) acoplado à base lexical.

\begin{tabular}{|c|l|}
\hline $\begin{array}{c}\text { Estrutura interna } \\
\text { dos verbos }\end{array}$ & \multicolumn{1}{|c|}{ Verbos denominais/deadjetivais } \\
\hline$\left[[\mathrm{base}]_{\mathrm{RadN} / \mathrm{A}}\right]_{\mathrm{RadV}}$ & $\begin{array}{l}\text { alcatifar, alcatroar, ancorar, arbitrar, armazenar, azedar, } \\
\text { betonar, betumar, doutorar, } \text {, insultar, martelar, murar, olear, } \\
\text { perfumar, policiar, rubricar, temperar, vacinar... }\end{array}$ \\
\hline
\end{tabular}

Quadro IV.7. Verbos heterocategoriais conversos

Através da conversão, o radical nominal ou adjetival é integrado na classe dos verbos, sem que se lhe adicione ou retire qualquer segmento formal. O verbo derivado é então formatado com uma VT (invariavelmente - $a$-), que determina o padrão flexional daquele.

A conversão é atualmente um dos processos mais disponíveis para a formação de verbos em português. Para a vitalidade deste procedimento muito contribui (i) o facto de os verbos de tema 
em - $a$ - serem os mais representados na língua portuguesa, (ii) o de a conversão não apresentar constrições significativas ao nível da sua aplicação e (iii) o de ser um processo de formação de verbos semântica e aspetualmente neutro. A classe de verbos conversos é, pois, suscetível de ser ampliada a qualquer momento, sendo muito utilizada na adaptação de unidades lexicais importadas (checar, clicar, crashar, mailar), na linguagem expressiva e informal dos falantes mais jovens (chibar, stressar) e na formação neológica, literária ou não (fusionar, peritar, plasmar).

As constrições morfofonológicas na aplicação do processo de conversão são essencialmente as duas seguintes: este processo não opera com base em nomes terminados em vogal acentuada como romã, pó, pé, jacaré, e também não seleciona bases monossilábicas ( $t i l, v i l$, mau, só).

Porque não faz uso de nenhum recurso afixal, tem um domínio de aplicação muito abrangente. Pode aplicar-se a bases iniciadas ou não por vogal (açúcar: açucarar; estranho: estranhar; irmão: irmanar; óleo: olear; último: ultimar; pincel: pincelar; lixa: lixar), a bases terminadas em qualquer tipo de segmento (remo: remar; pele: pelar; lixa: lixar; perdão: perdoar; questão: questionar; assessor: assessorar; pincel: pincelar).

Este processo pode aplicar-se quer a bases simples (lixar, luxar), quer a bases complexas, derivadas (enchumaçar, sacholar, ovalar) ou compostas (mata-bichar, vangloriar). Em presença de bases terminadas em -cion, -sion, -tion (acionar, adicionar, rececionar, convencionar, convulsionar, congestionar), -ment(o) (argumentar, complementar, condimentar, documentar, regulamentar), -nç(a) e -nci(a) (agenciar, conferenciar, diligenciar, licenciar, potenciar), -sor e -tor (assessorar, doutorar, tutorar), a conversão em -ar é o processo normalmente ativado, embora em alguns casos em competição com alguns processos afixais, principalmente -iz- (assessor (iz)ar, caricatur(iz)ar, monitor(iz)ar). 
Em termos semânticos, como ficou explícito em 4.3.2., a formação de verbos por conversão recorre preferencialmente a adjetivos 'de fase', i.e., adjetivos que descrevem propriedades transitórias ou ocasionais de entidades que podem ser mudadas por uma causa, como as suas caraterísticas físicas (cf. azul/azular, oval/ovalar), e não a adjetivos que designam 'propriedades de indivíduo'. As bases adjetivais denotam, entre outras, propriedades apreendidas pelos sentidos (azul, amarelo, azedo), propriedades que exprimem uma avaliação física ou intelectual (caduco, tísico, roliço, autêntico, malu$c o$ ), propriedades relativas às relações interpessoais (amásio, amigo).

As bases nominais dos verbos formados por conversão têm traços semânticos diversificados, designando seres humanos (assessor, doutor, peregrino), animais (caracol, macaco), vegetais (grelo, urtiga), substâncias naturais (açúcar, mel, couraça) ou químicas (iodo, estanbo), objetos construídos (buzina, máscara, sacho), fenómenos meteorológicos (granizo, orvalbo), sentimentos (inveja, ódio, orgulbo).

Não funcionam como base de verbos conversos os seguintes tipos de nomes: (a) de evento denominais em -ad(a) (*cabeçadar, *cotoveladar, *belenzadar); (b) agentivos deverbais em -dor (*varredorar, *fumadorar); e (c) deadjetivais em -idad(e) (*amabilidadar, *claridadar).

Em contraste com os processos afixais de formação de verbos, que intervêm diretamente na especificação semântico-aspetual dos verbos por eles formados, a conversão funciona tipicamente com um valor aspetualmente neutro ou não marcado (Pena 1993; Coelho 2003; Rio-Torto 2004). Na ausência de um afixo que aporte uma significação particular, o significado do verbo converso é construído e interpretado em função do significado prototípico da base lexical e/ou do seu uso típico e de informações co(n)textuais, i.e., informações semântico-conceptuais fornecidas pelos restantes argumentos da frase e pelo conhecimento enciclopédico que os falantes possuem da realidade.

Trata-se de um processo em que a instrução semântica de 'mudança de estado-de-coisas', associada ao valor semântico da base, 
possibilita a criação de verbos com valores semânticos diversificados. Assim, o verbo converso pode ser locativo (armazenar: 'pôr algo em armazém'), resultativo (azular: 'tornar azul'), ornativo (açucarar: 'pôr açúcar em algo'), instrumental (martelar: 'bater com martelo'), performativo (vindimar: 'fazer a vindima') e modal (arbitrar: 'agir como árbitro').

Os verbos conversos são predominantemente causativos, admitindo em alguns casos uma variante incoativa (lesionar / lesionar-se; secar / secar-se).

\subsubsection{Verbos formados por prefixação}

Um segundo grupo de verbos derivados integra na sua estrutura interna um prefixo ( $a$-, en- ou es-) e uma base nominal ou adjetival; a vogal temática (VT) - $a$ - inscreve-os no paradigma flexional da $1 .^{a}$ conjugação. Usa-se a forma de citação, de infinitivo.

\begin{tabular}{|l|l|l|l|}
\hline $\begin{array}{c}\text { Estrutura interna } \\
\text { dos verbos }\end{array}$ & Verbos denominais/deadjetivais & $\begin{array}{c}\text { Total de } \\
\text { verbos } \\
\text { atestados }\end{array}$ & $\begin{array}{c}\text { Percentagem } \\
\text { de cada } \\
\text { prefixo }\end{array}$ \\
\hline$\left[\mathrm{a}[\mathrm{base}]_{\mathrm{RadN} / \mathrm{A}}\right]_{\mathrm{RadV}}$ & $\begin{array}{l}\text { abotoar, acalorar, adensar, } \\
\text { agravar, alongar, assustar, } \\
\text { atapetar, aterrar, avermelhar... }\end{array}$ & 1027 & $51.66 \%$ \\
\hline$\left[\mathrm{en}[\mathrm{base}]_{\mathrm{RadN} / \mathrm{A}}\right]_{\mathrm{RadV}}$ & $\begin{array}{l}\text { embelezar, encabar, encabeçar, } \\
\text { encaixar, encerar, engarrafar, } \\
\text { engordar, enlatar, enrolar, } \\
\text { entubar.. }\end{array}$ & 752 & $37.83 \%$ \\
\hline$\left[\mathrm{es}[\mathrm{base}]_{\mathrm{RadN} / \mathrm{A}}\right]_{\mathrm{RadV}}$ & $\begin{array}{l}\text { esboroar, esburacar, esfarelar, } \\
\text { esfarrapar, esfriar, esquentar, } \\
\text { esvaziar, esventrar... }\end{array}$ & 209 & $10.51 \%$ \\
\hline
\end{tabular}

Quadro IV.8. Verbos heterocategoriais prefixados e representatividade de cada prefixo no conjunto de verbos prefixados

$\mathrm{Na}$ ausência de operadores sufixais que assegurem a verbalização, os prefixos sob escopo têm a capacidade de transformar bases 
nominais e adjetivais em verbos. Através da prefixação de $a$-, en- e es- a bases nominais e adjetivais forma-se um novo radical verbal, que é formatado morfologicamente com uma informação temática $(-a-)$ que o insere num paradigma conjugacional 55 .

Como se observa no Quadro IV.8, no conjunto dos verbos prefixados, cerca de metade são formados com o prefixo $a$-, enquanto a outra metade compreende verbos formados em en- e em es-.

Trata-se de um processo formativo com grande representação na língua portuguesa e crescentemente operativo (cf. vive a assapar 'usar o SAPO'). Os verbos prefixados representam mais de metade dos verbos construídos por afixação (cf. Quadro IV.9). Num corpus com 3698 verbos heterocategoriais recenseados, os processos afixais encontram-se assim repartidos: 1988 verbos prefixados, 1466 sufixados e 244 circunfixados, nas percentagens que o quadro seguinte ilustra.

\begin{tabular}{|c|c|c|}
\hline Verbos prefixados & Verbos sufixados & Verbos circunfixados \\
\hline $53.76 \%$ & $39.64 \%$ & $6.60 \%$ \\
\hline
\end{tabular}

Quadro IV.9. Percentagem relativa dos diferentes tipos de afixação na formação de verbos

\subsection{Verbos prefixados com $a$ -}

Dos prefixos formadores de verbos denominais e deadjetivais em português, $a$ - é o prefixo com maior representatividade ( $\approx 52 \%$ ). Ocorre maioritariamente com a forma $a$ - (adoçar, alisar, apadrinhar,

55 A solução alternativa de considerar estes verbos formados por parassíntese ou circunfixação carece ainda de demonstração teórica convincente, para que a possamos adoptar sem reservas. O quadro de funções semânticas (quadro 12) desempenhadas pelos verbos formados quer por conversão quer por circunfixação (cf. cap. 4: 4.3.4) não permite também decidir num sentido diferente daquele pelo qual optamos neste livro. 
apavorar), mas em alguns casos manifesta ainda a sua antiga forma latina ad- (adunar 'reunir em um', verbo atestado já em latim).

$O$ prefixo $a$ - junta-se preferentemente a bases nominais (cerca de $80 \%$ ) e adjetivais (cerca de $20 \%$ ). Esporadicamente, encontram-se algumas bases de outras categorias (cf. acercar, apoucar, atuar, atroar, açular).

Do ponto de vista morfológico, as bases selecionadas pelo prefixo $a$ - são maioritariamente nomes e adjetivos simples. Existem, contudo, algumas bases complexas, de que se destacam as sufixadas em -an-: acastelhanar, aparoquianar; $-(\boldsymbol{a} / \boldsymbol{i} / \boldsymbol{u}) \boldsymbol{l} \boldsymbol{h}(\boldsymbol{a} / \boldsymbol{o})$ : avergalhar, aguerrilhar, apedregulhar; -eir(o/a): abrasileirar, acapoeirar; -eng-: amulherengar; -ês: aburguesar, achinesar; -ção: atraiçoar; -nt(e): abrilhantar, adormentar; -ment(o): ajuramentar, arregimentar.

Este processo não se aplica quando as bases apresentam determinadas estruturas morfológicas, com especial relevo para as bases prefixadas (cf. *ainvulgarar, *adescontentar) e para as bases sufixadas com -al (*anacionalar), -ar (*acircularar), -ic- (*aplasticar), -dor ("afumadorar) e -vel (*acomestibilar).

O prefixo $a$ - aplica-se maioritariamente a adjetivos qualificativos, que denotam propriedades ocasionais ou de fase, designando, entre outras, propriedades relativas (i) à forma (redondo/arredondar, liso/alisar, plano/aplanar), (ii) à cor (claro/aclarar, vermelho/ avermelhar), (iii) à dimensão (largo/alargar, miúdo/amiudar), (iv) aos sentidos (doce/adoçar) e (v) propriedades comportamentais, psicológicas e morais (cobarde/acobardar, palerma/apalermar). Entre as bases selecionadas, encontram-se também alguns adjetivos denominais de relação (e.g. palaciano, paroquiano), mas usados em sentido qualificativo.

Em relação às bases nominais, $a$ - seleciona bases que se inserem em classes semânticas muito diversas, designando: (i) objetos ou realidades concretas (tapete/atapetar); (ii) substâncias naturais ou químicas (chocolate/achocolatar); (iii) instrumentos ou armas em 
sentido lato (plaina/aplainar, punhal/apunhalar) (iv) recipientes ou lugares (prisão/aprisionar, quartel/aquartelar); (v) animais (carneiro/acarneirar); (vi) entidades humanas (padrinho/apadrinhar); (vii) estados psicológicos ou processos mentais (paixão/apaixonar, pavor/apavorar, susto/assustar).

Este prefixo forma normalmente verbos transitivos de valor causativo. Possui um valor semântico de natureza 'adlativa', e é um prefixo marcado por polaridade final, i.e., remete para o estado final da mudança de estado (alargar, assustar) ou de lugar (aprisionar) denotada pelo verbo derivado. Este seu valor semântico permite distinguir os verbos prefixados com $a$ - de verbos formados com outros prefixos, como aterrar/enterrar, ou sem prefixo (cf. aplanar/planar), que expressam eventos com orientações espaciais ou polaridades aspetuais diferentes.

\subsection{Verbos prefixados com en-}

Este prefixo pode ocorrer sob quatro variantes formais alternativas: en- (encerar, ensacar, enlatar), em- (empacotar, embebedar), e- (emalar (en+mala), enatar), e ainda uma variante de feição latiniforme in- (inseminar). Com exceção da forma in-, a ativação das demais variantes do prefixo é fonologicamente condicionada, ocorrendo em distribuição complementar: em- ocorre antes de [+bilabial, -nasal], $e$ - antes de [+nasal], e en-, por defeito, nos restantes cotextos. Saliente-se que, ao contrário do que se passa com o prefixo in- 'negativo' (imortal, irreal, ilíquido), com este prefixo ilativo não se verifica a perda de nasal antes de líquida (cf. enraizar, enlatar).

O prefixo en- junta-se preferentemente a bases nominais (cerca de 91\%); as bases adjetivais representam cerca de $9 \%$, e são quase exclusivamente iniciadas por consoante. As exceções são em número muito reduzido (enamorar, enouriçar). 
Do ponto de vista morfológico, as bases selecionadas pelo prefixo en- são maioritariamente nomes e adjetivos simples. Não se exclui, no entanto, que possam ser selecionadas algumas bases complexas. Encontram-se atestadas bases sufixadas em - ão: engarrafonar; - $(\boldsymbol{a} / \boldsymbol{i})$ $\boldsymbol{l h}(\boldsymbol{o} / \boldsymbol{a})$ : emborralhar, envasilhar; - $\boldsymbol{e i r}(\boldsymbol{o} / \boldsymbol{a})$ : enceleirar, encoleirar; -ugem: enferrujar; e ainda outras como em emburguesar, embelezar, engordurar. Tal como na formação de verbos com $a$-, as bases prefixadas não estão disponíveis para a adjunção de en-.

$O$ prefixo en-aplica-se maioritariamente a adjetivos qualificativos, que denotam qualidades ou estados transitórios, não permanentes (bêbedo, crespo, curto, curvo, direito, gordo, louro, prenhe, rijo, torto, turvo). O prefixo pode também selecionar adjetivos denominais de relação (burguês, soalheiro), desde que com sentido qualificativo.

Em relação às bases nominais, a prefixação com en- seleciona nomes que designam realidades semanticamente muito diversas: (i) objetos concretos (bandeira, tapete); (ii) substâncias naturais ou químicas (bálsamo, cera, palha); (iii) conjunto ou coletividade (fardo, parelha); (iv) recipientes ou lugares (caixa, cárcere, saco); (v) animais (cabrito, cavalo); (vi) seres humanos (bruxa, moleiro); (vii) estados psicológicos ou processos mentais (coragem, ciúme, vergonha).

Tal como $a$-, o prefixo en-forma normalmente verbos transitivos de valor causativo. Apresenta uma instrução semântica de natureza 'ilativa' ('para dentro de'), sendo marcado por polaridade final, i.e., remete para o estado final da mudança de estado/lugar denotada pelo verbo derivado. Em função deste valor semântico, os verbos prefixados com en- distinguem-se de verbos formados com outros prefixos (ensacar/assacar, enfarelar/esfarelar, enfarrapar/esfarrapar) ou sem prefixo (ensacar/sacar, enforjar/forjar, enlurar/lurar), que expressam eventos com orientações espaciais ou polaridades aspetuais diferentes. 


\subsection{Verbos prefixados com es-}

Este prefixo apresenta, ao lado da variante nativa es- (esboroar, esfriar, esventrar), uma variante formal de matriz latina, ex- (expatriar, expropriar), e uma variante $e$ - (evaporar). Entre os prefixos que formam verbos denominais e deadjetivais, es- é o que tem menor representatividade (cerca de $10 \%$ do total dos verbos prefixados).

O prefixo es- forma verbos a partir de bases nominais (95\%) ou adjetivais (5\%) iniciadas em segmento consonântico e preferentemente não complexas. Não se aplica a bases prefixadas, mas pode-se encontrar acoplado a bases sufixadas em $-(\boldsymbol{a} / \boldsymbol{i} / \boldsymbol{u}) \boldsymbol{l} \boldsymbol{b}(\boldsymbol{o} / \boldsymbol{a})$ : esmigalhar, esquartilhar, esbagulhar; -eir(o/a): esponteirar, escabeleirar; -ugem: espenujar; e ainda outras bases com sufixos de caráter avaliativo: estrancinhar, esmurraçar.

As bases adjetivais pertencem geralmente à classe dos adjetivos qualificativos que denotam qualidades ou estados transitórios, não permanentes, que admitem algum tipo de alteração ou modificação (frio, miúdo, quente, vazio). Por sua vez, as bases nominais distribuem-se por várias classes semânticas que denotam (i) objetos ou substâncias concretas (boroa, casca), (ii) estados, processos ou produtos resultantes desses processos (preguiça, murro), (iii) conjunto ou coletividade (conjunto, quadrilha); (iv) recipientes ou lugares (pipa, ventre); (v) animais (borrego, piolbo); (vi) instrumentos (foice, gadanbo).

Este prefixo forma normalmente verbos transitivos de valor causativo mas, ao contrário dos anteriores, possui um valor semântico de tipo elativo ('para fora de'), sendo em muitos casos marcado por 'polaridade inicial', i.e., remete para o estado inicial da mudança de estado/lugar denotada pelo verbo derivado (cf. espipar, esladroar). Quando as bases são denominais, os verbos derivados em es- têm uma leitura egressiva, por oposição aos verbos em $a$ - e $e n$-, de leitura tipicamente ingressiva. Esta situação verifica-se sobretudo quando 
estão envolvidos processos de tipo locativo ou ornativo (aprisionar, encerar, encarcerar vs. espipar, esventrar, espiolhar). Nos verbos deadjetivais, porque denotam normalmente uma mudança de estado com uma orientação final (cf. avermelhar, encurtar, esquentar, esvaziar), a distinção entre os prefixos esbate-se.

\subsubsection{Verbos formados por sufixação}

Um terceiro conjunto de verbos construídos a partir de bases nominais e adjetivais é o dos verbos sufixados. O sufixo ativado em cada caso (-iz-, -ific-, -it-, -ic-, -e(s)c-, -e-, -ej-) é o responsável pelas alterações semântico-categoriais instanciadas. No Quadro seguinte, os verbos aparecem no infinitivo, por se tratar da forma de citação.

\begin{tabular}{|c|c|c|c|}
\hline $\begin{array}{l}\text { Estrutura interna } \\
\text { dos verbos }\end{array}$ & Verbos denominais e deadjetivais & $\begin{array}{c}\text { Total de } \\
\text { verbos } \\
\text { atestados }\end{array}$ & $\begin{array}{c}\text { \% de } \\
\text { cada } \\
\text { sufixo }\end{array}$ \\
\hline$\left[[\text { base }]_{\text {RadN/A }} \mathrm{iz}\right]_{\text {RadV }}$ & $\begin{array}{l}\text { suavizar, canalizar, comercializar, } \\
\text { urbanizar... }\end{array}$ & 556 & $37.93 \%$ \\
\hline$\left[[\text { base }]_{\operatorname{RadN} / \mathrm{A}} \mathrm{e}\right]_{\mathrm{RadV}}$ & branquear, coxear, folhear, golpear... & 504 & $34.38 \%$ \\
\hline$\left[[\text { base }]_{\text {RadN/A }} \text { ej }\right]_{\text {RadV }}$ & fraquejar, gotejar, verdejar, versejar... & 178 & $12.14 \%$ \\
\hline$\left[[\text { base }]_{\text {RadN/A }} \text { ific }\right]_{\text {RadV }}$ & $\begin{array}{l}\text { simplificar, exemplificar, gelificar, } \\
\text { petrificar... }\end{array}$ & 151 & $10.30 \%$ \\
\hline$\left[[\text { base }]_{\text {RadN/A }} \mathrm{e}(\mathrm{s}) \mathrm{cer}\right]_{\mathrm{RadV}}$ & $\begin{array}{l}\text { escurecer, humedecer, favorecer, } \\
\text { florescer... }\end{array}$ & 47 & $3.20 \%$ \\
\hline$\left[[\text { base }]_{\text {RadN/A }} \text { it }\right]_{\text {RadV }}$ & capacitar, facilitar, debilitar... & 17 & $1.16 \%$ \\
\hline$\left[[\text { base }]_{\text {RadN/A }} \text { ic }\right]_{\text {RadV }}$ & duplicar, triplicar, multiplicar... & 13 & $0.89 \%$ \\
\hline
\end{tabular}

Quadro IV.10. Verbos heterocategoriais sufixados e representatividade de cada sufixo no conjunto de verbos sufixados

Tal como acontece com os verbos prefixados, também alguns verbos sufixados convivem com formações corradicais não sufixadas com significados semelhantes (e.g. assessorizar/ assessorar; boicotear/boicotar; monitorizar/monitorar). Todavia, uma análise semântica mais profunda permite identificar diferenças semântico- 
-referenciais entre produtos corradicais sufixados e não sufixados, como se observa em alfabetizar 'instruir' vs. alfabetar 'pôr por ordem alfabética' e vaporizar 'transformar em vapor, aplicar vapor' e evaporar 'fazer desaparecer como o vapor'.

Embora se trate de recursos cofuncionais, que concorrem na formação de verbos em português, nem todos os sufixos verbalizadores têm a mesma representatividade na língua (cf. Quadro IV.10), e as condições de funcionamento de cada um são parcialmente diferentes.

De seguida descrevem-se e analisam-se as bases selecionadas pelos sufixos mais representativos na formação de verbos heterocategoriais em português.

\subsection{Verbos sufixados com -e-}

Os verbos sufixados com -e- tomam por base radicais nominais e adjetivais, como em [alt]ear, [clar]ear, [bombard]ear, [farsant] ear, [flor]ear, [galant]ear, [nort]ear, [prat]ear, [pent]ear, [serpent] ear, [sort]ear, [tour]ear ${ }^{56}$.

A maioria das formações em - $e$ - tem origem em unidades não complexas de categoria nominal (85\%) e adjetival (15\%). Na base dos verbos em -e-, existem, no entanto, algumas bases complexas, compostas (barlaventear, nordestear, noroestear, sotaventear) e derivadas. Entre estas encontram-se adjetivos com bases sufixadas em -os-: formosear, mimosear; -ão: fanfarronear, pimponear; -nt(e): fulgentear, farsantear, galantear, pedantear, tratantear. Entre os nomes, encontram-se bases sufixadas com -et(e/a): colchetear, cornetear, ferretear, falsetear, floretear, foguetear, joguetear; carretear, palbetear, trombetear.

56 Nos verbos alhear, arear, vergontear, o segmento - $e$ - não faz parte do corpo do sufixo, mas da base (alheio $>[$ alhe $]$ ar; areia $>[$ are $]$ ar; vergôntea $>[$ vergonte $]$ ar). 
As bases adjetivais são maioritariamente adjetivos qualificativos, que denotam qualidades ou estados transitórios, não permanentes, que admitem alteração ou modificação (alto, branco). As bases nominais são semanticamente mais heterogéneas, compreendendo nomes que designam (i) objetos ou realidades concretas (balança, bala, barba); (ii) substâncias naturais ou químicas (bronze, prata); (iii) animais (borboleta, serpente); (iv) agentes de atividades profissionais ou outras (capitão, pastor); (v) seres humanos caraterizados pela sua maneira típica ou habitual de atuar ou proceder, quase sempre valorada negativa ou pejorativamente (charlatão, fanfarrão, farsante, gandulo); (vi) estados, processos ou produtos resultantes desses processos (alarde, boicote, coice); (vii) sentimentos ou sensações (escrúpulo, sabor); (viii) instrumentos (espora, trombeta); (ix) recipientes, lugares ou denominações de indicações espaciais (fundo, nordeste, sotavento).

Este sufixo forma verbos transitivos de valor causativo (branquear: 'fazer ficar branco'), embora em alguns co(n)textos se encontrem verbos intransitivos e não causativos (coxear 'andar coxo', e não * fazer ficar coxo). Em muitos casos, o verbo derivado é transitivo, mas admite usos de tipo inacusativo (a lixívia branqueou a roupa. / a roupa branqueou ao sol.).

Os verbos em - $e$ - inscrevem-se em classes semânticas diversificadas: (i) resultativos (branquear, clarear, falsear), ornativos (gradear, presentear), locativos (flanquear, fundear, nortear), instrumentais (chicotear, pentear), performativos (boicotear, chacotear) e modais (coxear, capitanear, pavonear).

Embora o sufixo - $e$ - forme verbos que exprimem uma mudança de estado-de-coisas caraterizável como uma passagem de um dado estado (-E) para outro estado (E) designado pela base derivacional, distingue-se de outros processos verbalizadores (com exceção da sufixação com -ej-) relativamente à telicidade dos eventos descritos. Alguns verbos, principalmente deadjetivais, admitem leituras télicas (cf. a roupa branqueou em /durante duas horas; a Ana bronzeia-se em/ 
durante dois dias); mas os verbos em -e- são maioritariamente atélicos, i.e., não possuem um ponto terminal inerente (cf. chantagear durante / "em um ano; borboletear ou chicotear durante / "em cinco minutos).

Os verbos em - $e$ - formados a partir de bases que predicam uma propriedade pejorativa de nomes [+humano] (cf. charlatanear, coxear, farsantear, vagabundear) denotam eventos com um aspeto habitual ou frequentativo, ou seja, eventos repetidos, com a particularidade de a pluralidade, intermitência ou repetição dos eventos ocorrer de modo descontínuo, em distintos intervalos de tempo (Pena 1993: 242).

Os verbos cuja base denota algum tipo de instrumento (cf. chicotear, esporear) ou objeto movido ou atuado (cf. bombardear, folhear) são geralmente eventos iterativos, ou seja, denotam uma série sucessiva de eventos acabados de duração interna mínima (momentâneos ou pontuais), realizados num intervalo de tempo definido, integrando um único e mesmo processo.

Em suma, em resultado do(s) tipo(s) de bases que toma, o sufixo -e- projeta frequentemente um traço aspetual [-télico] nos verbos derivados, sendo, em muitos casos, esta informação aspetual concomitante com a ideia de iteratividade ou habitualidade.

\subsection{Verbos sufixados com $-e j$ -}

Embora existam verbos formados com base em onomatopeias (cf. cacarejar, traquejar), a maioria dos verbos derivados com -ej- tem uma origem nominal ou adjetival, com uma clara preferência para as bases nominais (cerca de $84 \%$ dos verbos derivados).

Não havendo restrições de natureza fonológica, as bases selecionadas são maioritariamente adjetivos e nomes simples (cf. fraco $>$ [fraqu]ejar; festa $>$ [fest]ejar; vara $>$ [var]ejar $)$.

As bases adjetivais são maioritariamente adjetivos qualificativos, denotando qualidades ou estados transitórios, que admitem alteração 
ou modificação (branco, fraco, manco). A maioria das bases adjetivais refere-se a sensações visuais, com particular incidência nos adjetivos de cor (branco, verde). Já as bases nominais podem pertencer a várias classes semânticas, designando: (i) objetos ou realidades concretas (grade, lágrima, trave); (ii) animais (cobra, corvo); (iii) agentes de atividades profissionais ou outras (carpinteiro, pastor), (iv) atos, processos e/ou estados resultativos (brado, festa), (v) sentimentos ou sensações (raiva); (vi) instrumentos ou entidades movíveis (rabo, vara); (vii) recipientes (forno).

O processo de formação de verbos com o sufixo - ej- é muito semelhante ao de -e-. O sufixo - ej-forma verbos transitivos de valor causativo (festejar: 'fazer (ficar em) festa') e verbos intransitivos e não causativos (gaguejar, gotejar), com algum predomínio destes. Tal como -e-, produz com alguma regularidade verbos com valor iterativo (gotejar, tracejar, varejar) ou habitual (doidejar, gaguejar). A iteratividade manifesta-se quando o sufixo toma como base nomes que denotam instrumentos (pestanejar, varejar) ou entidades efetuadas (gotejar), enquanto a habitualidade tende a marcar verbos de significado modal, cuja base remete para um defeito físico, psicológico ou moral (doidejar, praguejar).

Este sufixo rivaliza com outros processos derivacionais na produção de verbos de valor semântico (i) resultativo (branquejar, fraquejar), ornativo (torrejar, travejar), locativo (fornejar, proejar), instrumental (varejar, pestanejar), performativo (cortejar, praguejar) e modal (gaguejar, pastorejar).

\subsection{Verbos sufixados com $-e(s) c$ -}

Este sufixo encontra-se atestado em português sob duas variantes formais: -ec- (obscurecer, favorecer) e -esc- (ruborescer), variante latina ou erudita. 
A percentagem de verbos denominais ou deadjetivais sufixados com -e $(s) c$ - é bastante reduzida (pouco mais de 12\%) se comparada com a de outros operadores sufixais 57 .

O sufixo -e(s)c- seleciona bases maioritariamente simples, adjetivais $(62 \%)$ e nominais (38\%); ambas designam estados ou situações suscetíveis de serem atingidos (cf. bolorecer 'ganhar bolor', escurecer 'pôr algo escuro', robustecer 'tornar algo ou alguém robusto').

As bases adjetivais são maioritariamente adjetivos qualificativos que denotam qualidades ou estados não permanentes, que admitem alteração ou modificação. As bases adjetivais denotam qualidades físicas (amarelo, escuro, húmido) e qualidades mais abstratas de caráter psicológico ou moral (brando, estúpido, nobre). As bases nominais também podem pertencer a classes semânticas diferenciadas, designando (i) produtos decorrentes de processos naturais (bolor, erva, grumo), ou (ii) sentimentos ou sensações (orgulbo, ranço).

Os verbos em - $e(s) c$ - denotam geralmente uma 'mudança de estado ou qualidade' de caráter télico (cf. o dia escurece em trinta minutos; a Ana humedeceu os lábios em dois segundos). Trata-se de um conjunto de verbos semanticamente pouco diversificado, constituindo apenas duas classes semânticas: (i) resultativos (escurecer, humedecer) e performativos (favorecer).

A maioria dos verbos assim formados tanto expressa eventos incoativos como causativos (escurecer: 'ficar escuro', 'tornar escuro' ou 'fazer ficar escuro'). Não obstante ter uma clara vocação, herdada do latim, para a expressão de situações incoativas, $-e(s) c$ - não possui, na sincronia atual, um valor semântico-aspetual específico que o oponha aos demais processos/afixos verbalizadores. De facto, outros processos competem com ele na expressão da incoatividade e da causatividade.

${ }^{57}$ Nesta contabilização não entram os verbos terminados em -ecer que atualmente não possuem uma estrutura composicional, como aborrecer, acontecer, aparecer, conhecer, fenecer, guarnecer, padecer, perecer. 
Em função do tipo de evento denotado, os verbos em -e(s)c-podem ter uma realização transitiva ou intransitiva (inacusativa): cf. o fumo escureceu as paredes / as paredes escureceram.

\subsection{Verbos sufixados com -ific-}

Nem todos os verbos presentemente terminados em -ific- devem ser considerados sufixados. Uma grande parte dos verbos em -ific- é formada em latim, de onde terá transitado para o português. Durante o seu percurso diacrónico algumas destas unidades verbais adquiriram propriedades idiossincráticas, fazendo com que não possuam atualmente a composicionalidade morfo-semântica que tinham em latim (cf. caprificar, nutrificar, tumeficar), e sendo portanto no presente interpretadas como verbos não derivados.

Em português, o sufixo -ific- forma verbos a partir de bases nominais (60\%) e de bases adjetivais (40\%) simples. Tratando-se de um modelo de formação originariamente latino, muitos dos radicais selecionados por -ific- têm uma forma erudita, que contrasta com a forma autóctone dessa unidade lexical: cf. acet- 'vinagre', alb- 'branco', aur- 'ouro', case- 'queijo', corpor- 'corpo', cruc- 'cruz', dulc- 'doce', frigor- 'frio', ign- 'fogo', len- 'leve, suave', let- 'alegre', lign- 'madeira', mund- 'limpo', putr- 'podre', rub- e russ- 'vermelho', san- 'são', etc. Em alguns casos, a seleção do alomorfe erudito está relacionada com o facto de este sufixo não se acoplar a radicais terminados em vogal ou ditongo nasal acentuados (pão: panificar; lã: lanificar).

As bases adjetivais são maioritariamente adjetivos qualificativos, que denotam estados ou propriedades que podem ser alterados por impulso de uma causa (amplo, claro, falso, puro, simples, sólido), repartindo-se por duas subclasses: (i) bases que denotam propriedades físicas ou sensoriais (amplo, claro, denso, líquido, sólido) ou (ii) qualidades mais abstratas de caráter psicológico, subjetivo ou moral 
(beato, digno, santo). As bases nominais distribuem-se igualmente por duas classes semânticas: (i) objetos ou substâncias concretas (osso, pão, pedra, vinho, vidro), ou (ii) estados, qualidades e/ou produtos resultantes de um processo (classe, dano, exemplo, glória, paz).

Os verbos sufixados com -ific- são semanticamente diversificados (embora não tanto como -e- ou -iz-, por exemplo), estando atestados verbos (i) resultativos (amplificar, beatificar, falsificar, petrificar), ornativos (exemplificar), locativos (crucificar) e performativos (danificar, nidificar). Trata-se de um recurso derivacional com grande implantação em alguns domínios técnico-científicos, nomeadamente na Medicina e na Química.

Tanto os verbos denominais como os verbos deadjetivais em -ific- expressam um processo delimitado de mudança, denotando eventos causativos e télicos (cf. clarificarei a situação em/durante dois minutos; a gelatina solidifica em/durante duas horas). Esta classe derivacional de verbos designa uma 'mudança de estado ou qualidade' com um resultado inerente, que é expresso pela base derivacional.

Os verbos em -ific-são tipicamente transitivos, podendo, alternativamente, ser realizados de forma intransitiva (inacusativa), quando se prescinde da expressão do argumento externo causador (cf. o João clarificou a situação / a situação clarificou-se; o calor solidificou a massa / a massa solidificou).

\subsection{Verbos sufixados com -iz-}

O conjunto dos verbos derivados por intermédio do sufixo -iz- é, juntamente com os derivados com -e-, um dos grupos mais representativos (cerca de 38\%) de verbos formados por sufixação (cf. Quadro IV.8), sendo esse um dos fatores que ajuda a explicar a sua elevada disponibilidade atual. 
O sufixo -iz-junta-se a bases nominais e adjetivais (51,5\% e $48,5 \%$, respetivamente) para formar novos verbos.

Por vezes o verbo derivado admite duas ou mais leituras, remetendo para bases morfológica e/ou categorialmente diferentes. Tal acontece sobretudo em verbos em -iz-derivados de bases de origem grega, e em relação aos quais existem séries derivacionais que integram, além dos verbos em -iz-, adjetivos denominais em -ic- e nomes em -i(a).

Os verbos aromatizar, climatizar, dramatizar, dogmatizar, esquematizar têm por base um radical nominal alomórfico (aromat-, climat-, dramat-, dogmat-, esquemat-), desencadeado na presença do sufixo -iz-. Trata-se de bases que já no grego clássico apresentavam radicais variantes (e.g. dógma, dogmatos; drãma, dramatos) e que, em contexto derivacional, adotavam formas alomórficas terminadas em -t (cf. [dogmat]izar, [dogmat]ico, [dogmat]ismo; [dramat]izar, [dramat]ico, [dramat]ismo, etc.). Situação semelhante ocorre com os verbos catequizar, hipnotizar, sintetizar, pois a base nominal adota, em contexto derivacional, uma variante alomórfica terminada em oclusiva dental / $t /$ (cf. síntese: [sintet]izar, [sintét]ico).

No caso dos verbos do tipo de atomizar, hiperbolizar, profetizar, as paráfrases lexicográficas remetem ora para uma base nominal (átomo, hipérbole, profeta), ora para uma base adjetival (atómico, hiperbólico, profético). Situação idêntica ocorre em verbos como economizar, harmonizar, ironizar, relacionáveis com bases nominais terminadas em - $i(a)$ ou com bases adjetivais terminadas em -ic- (cf. economizar: 'administrar com economia; tornar económico'; harmonizar: 'tornar harmónico; estabelecer harmonia entre'; ironizar: 'tornar irónico; exprimir com ironia; empregar ironia'). Não havendo evidências de que não sejam denominais, é esta a interpretação que aqui se privilegia, pois a presença do sufixo -icdos adjetivos respetivos não se faz sentir no derivado, como seria 
composicionalmente expectável (cf. atomicizar, democraticizar, economicizar, harmonicizar, ironicizar).

O sufixo - iz- acopla-se preferencialmente a bases terminadas em consoante, embora também se combine com bases terminadas em vogal (europe $(u)$ : europeizar; plebe $(u)$ : plebeizar; homogéne $(o)$ : homogeneizar). ). Não se anexa, todavia, a radicais terminados em vogal acentuada ou ditongo nasal, recorrendo nestes casos a alomorfes eruditos (homem: hominizar).

A adjunção de -iz-também não apresenta restrições de caráter morfológico, podendo acoplar-se a bases simples (suavizar) ou complexas, sobretudo derivadas, domínio em que se notam solidariedades afixais importantes. Com efeito, entre as bases selecionadas abundam os adjetivos denominais em -al (atualizar, comercializar, criminalizar), -an- (africanizar, americanizar), -ar (familiarizar), -ic- (heroicizar), -il (febrilizar, infantilizar), -in- (masculinizar), e também adjetivos deverbais em -vel (compatibilizar, contabilizar). Entre as bases nominais encontram-se numerosas bases de origem grega em -i(a) (agonizar, simpatizar, harmonizar, ironizar). Refira-se ainda que o sufixo - iz-se pode acoplar a bases prefixadas com in- (infertilizar, impopularizar, insensiblizar, inutilizar).

No domínio das bases simples, -iz- concorre com outros processos morfológicos de formação de verbos; mas a morfologia marcada das bases complexas selecionadas por -iz-faz dele um sufixo que tende a estar em distribuição complementar com outros processos afixais, ocupando as lacunas por estes não preenchidas. As bases morfologicamente complexas incompatíveis com outros afixos são facilmente selecionadas pela sufixação em -iz-, como se observa em *anacionalar, *encontabilar, *materialear, *regularificar, frente a nacionalizar, contabilizar, materializar, regularizar.

As bases adjetivais selecionadas podem denotar propriedades físicas (ameno, estéril, frágil, imune, suave) e qualidades de natureza comportamental, psicológica ou moral (austero, célebre, cretino, 
fraterno). Estas bases são quer adjetivos qualificativos que denotam qualidades ou estados transitórios, podendo ser alterados ou modificados pela intervenção de uma causa (ameno, célebre, eterno, severo), quer adjetivos relacionais (comercial, familiar, masculino, heroico, urbano). Os adjetivos de relação, quando bases de derivação, são reinterpretados como qualificativos, mais exatamente como adjetivos caraterizadores de um tipo ou maneira habitual de ser ou comportar-se (cf. africanizar(-se): 'dar/tomar caráter africano'; americanizar(-se): 'dar/tomar caráter americano').

As bases nominais podem pertencer a várias classes semânticas, designando (i) objetos ou substâncias concretas (álcool, aroma, carvão), (ii) estados e/ou propriedades (amante, mártir), (iii) sentimentos, sensações e/ou estados de espírito (borror, trauma, simpatia), (iv) o produto/resultado de um processo (catequese, esquema, teoria), (v) entidades [+humanas], interpretadas geralmente como agente típico ou habitual (apóstolo, fiscal, profeta), (vi) propriedades relacionadas com um nome próprio (Maquiavel, Píndaro), (vii) instrumentos (binóculo, estilete), (viii) lugares ou recipientes (hospital, memória).

Os verbos derivados por intermédio do sufixo -iz-são semanticamente muito diversificados, podendo pertencer a várias classes semânticas: (i) resultativos (atualizar, martirizar), ornativos (aromatizar, hifenizar), locativos (hospitalizar, memorizar), instrumentais (estiletizar, escalpelizar), performativos (esquematizar, hipnotizar) e modais (fiscalizar, profetizar). A maioria destes verbos, sejam deadjetivais (agudizar, agilizar, fertilizar, inutilizar) ou denominais (cristalizar, carbonizar, consonantizar, horrorizar, traumatizar), admite uma leitura télica (cf. a Ana inutilizou o cheque em/*durante cinco segundos; o fogo carboniza a lenha em/*durante cinco minutos); os verbos de processo, cuja base designa uma realidade [+abstrata] produzida ou experienciada ou um ser dotado de propriedades agentivas, tendem a ter uma leitura atélica (cf. o cão 
agonizou durante meses/*em dois minutos; o sacerdote profetizou essa situação durante/*em três anos).

O sufixo -iz-forma tipicamente verbos causativos de realização transitiva (cf. modernizar: 'fazer ficar moderno'; traumatizar: 'fazer ficar com trauma'). No entanto, como em outras classes afixais de verbos, estes verbos admitem também, alternativamente, a expressão de eventos incoativos na realização intransitiva (inacusativa): cf. o Governo modernizou o país / o país modernizou-se; a reportagem horrorizou os portugueses / os portugueses horrorizaram-se com a situação.

\subsection{Verbos sufixados com -it-}

O sufixo -it- forma verbos a partir de bases adjetivais simples geralmente terminadas em lateral (fácil > facilitar; débil > debilitar) e sibilante (feliz > felicitar; capaz > capacitar), não devendo ser confundido com a forma homónima que intervém na formação de verbos deverbais (cf. 4.4.1.).

Em termos semânticos, os verbos deadjetivais em -it- são resultativos, tratando-se de verbos tipicamente transitivos e causativos (cf. a nova lei facilita os despedimentos; a febre debilitou-o).

\subsection{Verbos sufixados com -ic-}

O conjunto de verbos derivados por intermédio do sufixo -ic- é, juntamente com os derivados com -it-, um dos grupos menos representativos de verbos formados por sufixação (cf. Quadro IV.8). Como toma por bases quantificadores numerais (multiplicativos), não são expectáveis novas formações com esta estrutura morfológica.

Os verbos sufixados com -ic- são semanticamente homogéneos, pertencendo à classe dos verbos resultativos (cf. duplicar, triplicar: 
'tornar duas/três vezes maior'). Estes verbos são tipicamente transitivos e causativos, admitindo alternativamente, tal como outras classes afixais de verbos, a expressão de eventos incoativos na realização intransitiva (cf. Portugal duplicou as exportações de calçado / as exportações de calçado duplicaram).

\subsubsection{Verbos formados por circunfixação}

O grupo de verbos morfologicamente mais complexo integra na sua estrutura interna uma base que apresenta, à sua esquerda e à sua direita, um afixo. No quadro que se segue apresentam-se as estruturas circunfixadas e respetivas taxas de representatividade no conjunto de verbos através deste processo derivacional.

\begin{tabular}{|c|c|c|c|}
\hline $\begin{array}{l}\text { Estrutura } \\
\text { interna dos } \\
\text { verbos }\end{array}$ & Verbos denominais/deadjetivais & $\begin{array}{l}\text { Total de } \\
\text { verbos } \\
\text { atestados }\end{array}$ & Percentagem \\
\hline [a [base] e(s)c] & amadurecer, amolecer, apodrecer... & \multirow{3}{*}{119} & \multirow{3}{*}{$48.77 \%$} \\
\hline [en [base] e(s)c] & emagrecer, embolorecer, emudecer... & & \\
\hline [es [base] e(s)c] & esclarecer, espavorecer... & & \\
\hline [a [base] e] & acobrear, assenhorear... & \multirow{3}{*}{71} & \multirow{3}{*}{$29.10 \%$} \\
\hline [en [base] e] & enramear, enlamear... & & \\
\hline [es [base] e] & esfomear, esfaquear, espernear... & & \\
\hline [a [base] ej] & anegrejar, apedrejar... & \multirow{3}{*}{19} & \multirow{3}{*}{$7.79 \%$} \\
\hline [en [base] ej] & enverdejar, encarvoejar... & & \\
\hline [es [base] ej] & esquartejar, esbracejar... & & \\
\hline [a [base] ent] & amolentar, apodrentar, avelhentar... & \multirow{2}{*}{16} & \multirow{2}{*}{$6.56 \%$} \\
\hline [en [base] ent] & endurentar, enfraquentar... & & \\
\hline [a [base] iz] & atemorizar, aterrorizar... & \multirow{3}{*}{14} & \multirow{3}{*}{$5.73 \%$} \\
\hline [en [base] iz] & encolerizar, entronizar & & \\
\hline [es [base] iz] & espavorizar, esfossilizar & & \\
\hline $\begin{array}{l}\text { [pref [base]ic/ } \\
\text { ific/eg] }\end{array}$ & $\begin{array}{l}\text { apanicar, espenicar, escarnificar, } \\
\text { espedregar, espernegar }\end{array}$ & 5 & $2.05 \%$ \\
\hline
\end{tabular}

Quadro IV.11. Verbos heterocategoriais parassintéticos e representatividade de cada uma das estruturas circunfixadas no conjunto de verbos formados por parassíntese 
Estes verbos são tradicionalmente conhecidos como parassintéticos, considerando-se a parassíntese como a adição simultânea de um prefixo e de um sufixo a uma base ${ }^{58}$. A parassíntese deve ser diferenciada da adjunção, em momentos derivacionais distintos, de um prefixo e de um sufixo, ou vice-versa. Em palavras como inconsolável, insensatez, recalcetamento ou desconsideração, a prefixação e a sufixação não se dá de forma simultânea mas sucessiva, ou seja, são palavras formadas por sufixação seguida de prefixação (sensatez > insensatez; consolável > inconsolável; calcetamento > recalcetamento; consideração $>$ desconsideração) ou por prefixação seguida de sufixação (insensat $(o)>$ insensatez; recalceta $(r)>$ recalcetamento; desconsidera $(r)>$ desconsideração).

Para sabermos se uma palavra é formada por parassíntese ou por duas operações sucessivas de afixação podem ser utilizados dois critérios. Em termos formais, diz-se que dois processos de afixação são simultâneos se, ao suprimirmos qualquer dos afixos (prefixo ou sufixo), não existirem os produtos lexicais intermédios. Por exemplo, o verbo envelhecer é formado por parassíntese dado que nem *envelho, nem *velhecer são palavras da língua. Todavia, este critério formal revela-se, por vezes, falível e insuficiente. Em alguns casos, a supressão do sufixo (anegrejar / anegrar; encalecer / encalar) ou do prefixo (embolorecer / bolorecer; elanguescer / languescer) tem como resultado uma palavra existente, sem que isso ponha em causa a estrutura parassintética dos verbos com prefixo e sufixo.

Em complemento ao critério formal recorre-se a um critério semântico: uma formação parassintética tem um significado composicional para o qual concorrem simultânea e solidariamente prefixo e sufixo. Para que um verbo possa ser considerado parassintético é necessário que o seu significado remeta para uma base nominal ou adjetival e não para algum verbo não prefixado e/ou não sufi-

58 Ver, entre outros, Darmesteter (1972), Corbin (1987), Pena (1991). 
xado, atestado ou possível (cf. atemorizar: 'causar temor'/ *fazer temorizar, *fazer atemorar).

A coexistência de formações corradicais só prefixadas (assenhorar) ou só sufixadas (penejar, sanguificar) com formações simultaneamente prefixadas e sufixadas (assenhorear, espenejar, ensanguentar) demonstra que a presença do sufixo não é uma condição necessária para a presença do prefixo, sendo também verdadeiro o inverso. Os prefixos e sufixos atestados nestas formações ([a]temor[iz]ar, [en] surd[ec]er ou [es]verd[e]ar) ocorrem também de forma isolada, com condições de aplicação semelhantes, configurando casos de sufixação (branqu[e]ar, cort[ej]ar, escur[ec]er, horror[iz]ar) e de prefixação ([a]tapetar, [en]curtar, [es]vaziar). Os constituintes prefixais e sufixais presentes nos verbos parassintéticos manifestam valores semântico-aspetuais semelhantes, embora menos diversificados, aos que apresentam isoladamente, quando estes ocorrem de forma independente em prefixação e sufixação (ver secções 4.3.2.2. e 4.3.2.3.).

Como hipótese alternativa, pode considerar-se que os verbos com esta estrutura são formados por circunfixação ${ }^{59}$, um processo morfológico que recorre a um circunfixo, i.e., a uma unidade afixal descontínua que rodeia a base ([Af $\left.\left.\mathrm{f}_{\mathrm{i}}[\mathrm{b} a \mathrm{se}] \mathrm{Af}_{\mathrm{i}}\right]\right)$. Segundo esta proposta, em verbos do tipo de amadurecer, apedrejar ou encolerizar, os segmentos colocados à esquerda e à direita da base não possuem verdadeiramente o estatuto de prefixos e sufixos, mas constituem um circunfixo (e.g. a-...-ec-, a-...-ej-, en-...-iz-). A consideração destes verbos como circunfixados tem a vantagem de enquadrar este mecanismo derivacional numa tipologia abrangente de operações afixais e permite corresponsabilizar ambos os operadores afixais envolvidos, e não apenas o sufixo, pela

59 Ver, entre outros, Rio-Torto (1994, 1998b, 1998d, 2004), Spencer (1991, 1998), Pena (1999), Hall (2000), Mel'čuk (2000). 
mudança semântico-categorial processada. Subsistem, no entanto, questões por esclarecer relativamente à razão de ser destes padrões de circunfixação em português, pois são idênticas as condições de aplicação e os valores semânticos destes constituintes quando ocorrem em circunfixação e de forma independente.

É relativamente reduzido o número de verbos (244) denominais ou deadjetivais circunfixados (cf. Quadro IV.9), sobretudo por comparação com o número de verbos sufixados ou prefixados. O conjunto deste tipo de verbos representa apenas cerca de $6,6 \%$ do total de verbos formados com recurso a afixos.

Ademais, é grande a desproporção entre as várias possibilidades estruturais de circunfixação. Mais de três quartos dos verbos denominais e deadjetivais formados por circunfixação possui as estruturas pref [base] $e(s) \operatorname{cer}(48,77 \%)$ e pref [base] ear $(29,1 \%)$. Cada um dos demais padrões representa $2 \%, 5 \%, 6 \%$ e quase $8 \%$, sendo de salientar a baixa produtividade do que envolve - iz-, sobretudo quando comparada com a do sufixo isoladamente considerado.

Neste procedimento derivacional, os prefixos e os sufixos, porque paradigmaticamente cofuncionais, tendem a reforçar-se na expressão de valores próximos ou complementares. Em alguns casos as alternâncias afixais não implicam mudanças pertinentes em termos semânticos (cf. abrutecer, embrutecer: 'tornar(-se) bruto'; abrasear, esbrasear: 'pôr em brasa'; abolorentar, embolorecer: 'criar ou ganhar bolor'). Em outros casos os verbos circunfixados possuem significados pontualmente opositivos: assenhorar: 'dar/ tomar modos de senhor(a)' vs. assenhorear: 'tornar(-se) senhor, apoderar-se de'; espenejar: 'sacudir as penas (a ave)' vs. penejar: 'escrever ou desenhar à pena'; ensanguentar: 'manchar, macular com sangue' vs. sanguificar: 'converter em sangue'.

Os processos de circunfixação não diferem grandemente dos restantes processos derivacionais que produzem verbos heterocategoriais quanto ao(s) tipo(s) de bases que selecionam. Tal como 
acontece nos restantes processos verbalizadores, tomam como base o radical de um nome ou de um adjetivo morfologicamente simples (e.g. a[podr]ecer, en[tron]izar, es[faqu]ear). Para além disso, estes procedimentos cicunfixais conciliam as constrições combinatórias evidenciadas pela prefixação e sufixação verbais, o que os torna processos derivacionais com condições de aplicação mais limitadas que os seus concorrentes.

\subsection{Verbos de estrutura [pref + base $+e$ ]}

A estrutura [pref [base] $e$ ] é caraterística dos verbos derivados a partir de uma base lexical através da adjunção simultânea de um elemento prefixal ( $a$-, en- e es-) e de um elemento sufixal - $e$-, sendo o verbo resultante integrado no paradigma dos verbos da $1 .{ }^{a}$ conjugação. Os verbos com esta estrutura morfológica, tal como os verbos sufixados em $-e$-, selecionam preferencialmente bases nominais (cerca de $86 \%$ ), embora também selecionem bases adjetivais (cerca de $14 \%$ ), quase sempre de estrutura morfológica não complexa.

Ao nível fonológico, as bases são iniciadas por segmento consonântico e nunca por segmento vocálico, uma tendência também manifestada pela prefixação em $a$-, en- e $e s-$.

As bases adjetivais são maioritariamente adjetivos qualificativos, denotando qualidades ou estados transitórios (roxo, tonto, verde). Por sua vez, as bases nominais designam geralmente objetos ou realidades concretas (brasa, cobre, lança), existindo ainda algumas que designam processos/resultado desse processo (guerra, pinote), estados físicos ou psicológicos (fome, receio) e denominações de orientação espacial (norte, nordeste).

Os verbos constituídos por [pref [base] $e$ ] são, em geral, verbos transitivos de valor causativo (acobrear: 'fazer ficar com cor de cobre'; enlamear: 'fazer ficar com lama'; esverdear: 'fazer ficar 
verde'), embora também existam alguns verbos intransitivos e não causativos (espernear: 'agitar as pernas violentamente').

Os verbos com esta estrutura podem, em função do significado da base selecionada, ter um sentido (i) resultativo (acobrear, ensenhorear, esverdear), (ii) ornativo (atorrear, enlamear, escantear), (iii) locativo (anordestear, encumear, escasquear), (iv) instrumental (alancear, esfaquear), (v) performativo (aguerrear, escoicear) ou (vi) modal (escabrear). Todavia, nem todos os esquemas circunfixados apresentam atualmente o mesmo poder formativo, não estando atestados verbos de estrutura a[base]ear com valor modal, nem verbos de estrutura en[base]ear com valor performativo, instrumental ou modal.

Os verbos formados através destes esquemas circunfixais admitem uma leitura [ \pm télica] em função do semantismo das bases: são télicos os verbos resultativos cuja base designa a(s) propriedade(s) que algo/alguém passa a ter (em maior grau) (acobreou o cabelo em dois minutos), e os verbos ornativos que têm por base nomes que designam um objeto deslocado para um determinado lugar/ recipiente (engradeou a varanda em duas horas); são atélicos os verbos performativos cuja base derivativa denota objeto efetuado ("escoiceou em dois minutos) e os verbos que significam 'mover/ tocar X' ("esperneou em dois minutos).

Em determinados co(n)textos, nomeadamente quando a base nominal designa um objeto movido ou um objeto efetuado, estes esquemas circunfixais permitem a produção de verbos de valor iterativo (espernear, escoicear, espinotear).

\subsection{Verbos de estrutura [pref + base $+e j]$}

Os verbos com a estrutura [pref [base] $e j$ ] são pouco numerosos (19 atestações), sendo formações com fraca vitalidade. 
O esquema circunfixal pref-...-ej- acopla-se a bases morfologicamente simples, iniciadas por segmento consonântico, preferindo as bases nominais (79\%) às adjetivais (21\%).

As bases adjetivais são maioritariamente adjetivos qualificativos que denotam qualidades ou estados que podem ser alterados por ação de uma causa (bravo, negro). Por sua vez, as bases nominais designam (i) entidades concretas (pedra, pano), (ii) processos ou resultado desses processos (trote, voo), (iii) unidades de medida ou parcelas (parte, quarto).

Em termos semânticos, este processo de formação de verbos é muito semelhante ao de tipo [pref [base] $e$ ]. Forma verbos causativos e transitivos (esquartejar: 'fazer ficar em quartos') a par de verbos não causativos e intransitivos (esbracejar). Os verbos derivados possuem significados diversos, estando atestados verbos resultativos (anegrejar, esquartejar), ornativos (encarvoejar), instrumentais (espanejar) e performativos (estrotejar). Os verbos resultativos e ornativos admitem uma leitura télica (esquartejou o animal em cinco minutos), mas não os performativos e instrumentais (cf. eles esbracejaram *em/durante cinco minutos).

Os verbos assim formados possuem, em alguns casos, um valor iterativo, denotando eventos cuja realização requer a repetição contínua de subeventos do mesmo tipo (apedrejar: 'atirar pedras'; esbracejar: 'agitar muito os braços'; esquartejar: 'dividir ou partir em quartos').

\subsection{Verbos de estrutura [pref + base $+e n t]$}

São escassos (16 atestações) os verbos formados com base nos esquemas circunfixais a-...-ent- (aformosentar, amolentar, apodrentar, arralentar, avelhentar) e en-...-ent- (endurentar, envelhentar) ${ }^{60}$.

60 Os verbos acrescentar, adormentar, aferventar, aviventar são deadjetivais, denotando 'tornar crescente, dormente, fervente, vivente'. Neste grupo de verbos, não 
Trata-se de verbos que possuem um significado resultativo (aformosentar, amolentar, avelhentar), denotando tipicamente eventos causativos e télicos (aformosentar: 'fazer ficar formoso').

As condições de ativação deste procedimento derivacional não são diferentes das que afetam os restantes processos de circunfixação . As bases são tendencialmente nomes e adjetivos qualificativos morfologicamente simples, iniciados por segmento consonântico.

\subsection{Verbos de estrutura [pref + base $+i z$ ]}

Os verbos circunfixados com a estrutura [pref [base] $i z$ ] têm uma escassa representação na língua (14 atestações), contrastando claramente com a grande representatividade dos verbos em -izformados por sufixação.

As bases selecionadas pelo esquema pref-...-iz-são maioritariamente nomes simples (fóssil, pavor, terror), embora existam também casos de bases adjetivas. Tal como nos demais esquemas circunfixais , as bases selecionadas por este processo derivacional são iniciadas por segmento consonântico e nunca por segmento vocálico.

As bases adjetivais denotam propriedades ou estados que podem ser atingidos por ação de uma causa externa ou interna (bárbaro, social). As bases nominais podem denotar (i) objetos ou realidades concretas (fóssil, trono) ou (ii) sentimentos ou estados psicológicos (cólera, temor, terror).

Este esquema formativo forma essencialmente verbos de significado resultativo (atemorizar, efeminizar, encolerizar), sendo residuais

há lugar a circunfixação, uma vez que o segmento - nt- integra a base, e não o sufixo. $\mathrm{Na}$ sincronia atual, existem ainda verbos terminados em -ent-, como abolorentar ('tornar bolorento' ou 'fazer ganhar bolor'), apeçonhentar ('tornar peçonhento' ou 'fazer ganhar peçonha'), ensanguentar ('tornar sanguento' ou 'manchar com sangue') que se podem relacionar derivacionalmente com um adjetivo ou com um nome; no entanto, só a leitura denominal permite analisá-los como circunfixados. 
os verbos com valor locativo (entronizar) e ornativo (esfossilizar). Estes verbos são predominantemente causativos e télicos.

\subsection{Verbos de estrutura [pref + base $+e(s) c]$}

Os verbos derivados de estrutura [pref [base] $e(s) c$ ] constituem o grupo mais numeroso de verbos circunfixados. Porque se trata de um padrão formativo muito antigo, inicialmente latino, mas depois também português, encontram-se verbos derivados com formatações morfofonológicas diversas. Por exemplo, incrudescer e encrudelecer são formados de maneira semelhante e têm um significado idêntico, mas os seus constituintes morfolexicais diferem formalmente (cf. in [crud] escer frente a en [crudel]ecer). Situação semelhante verifica-se com os membros dos pares intumescer/entumecer, incandescer/encandecer e invalescer/envalecer, que incluem portanto uma variante erudita e outra nativa, respetivamente, da mesma unidade lexical.

Os constituintes (prefixais e sufixais) destes verbos podem apresentar uma forma [+ erudita], como se observa através da configuração dos que integram in- e -esc- (e.g. incandescer, intumescer, inturgescer, invalescer), de origem latina.

As bases selecionadas pelo esquema pref-...-e(s)c-são preferencialmente adjetivais (76,5\%), embora também existam verbos formados a partir de radicais nominais (23,5\%). Neste aspeto, os esquemas circunfixais pref-...-e(s)c-distinguem-se dos que integram -iz-, que se acoplam de preferência a bases nominais (4.3.3.3.4.).

As bases nominais e adjetivais selecionadas são geralmente simples (grávida, pálido, quente) e iniciadas por segmento consonântico. Uma exceção é a de enaltecer.

As bases adjetivais são maioritariamente adjetivos qualificativos que denotam qualidades ou estados transitórios que se podem atingir mediante a ação de uma causa (maduro, mole, magro, pobre, 
rico, velho). Já as bases nominais podem designar (i) objetos ou realidades concretas (barba, bolor, dente, tronco), (ii) estados físicos ou psicológicos (febre, fúria, raiva), e (iii) espaços temporais (manhã , tarde, noite).

Estes esquemas circunfixais formam principalmente verbos resultativos (anoitecer, apodrecer, emagrecer, enfurecer, esclarecer) e performativos (embolorecer, encanecer). Em qualquer caso, os verbos denotam eventos télicos (cf. emagreceu dois quilos em duas semanas).

A maioria dos verbos de estrutura pref-...-e(s)c-tanto expressa eventos incoativos como causativos (amolecer: 'ficar mole', 'tornar mole' ou 'fazer ficar mole'). Em muitos casos, estes dois valores constituem duas possibilidades de realização do mesmo verbo: quando usado de forma transitiva, expressa normalmente um evento causativo (cf. o leite amoleceu o pão; esta situação enlouqueceu-o); omitindo-se a expressão da causa e realizando o verbo de forma intransitiva (inacusativa), expressa-se um evento incoativo (cf. o pão amoleceu; ele enlouqueceu).

\subsubsection{Síntese}

Em português, podem-se formar verbos a partir de bases adjetivais ou nominais, recorrendo a várias operações morfológicas:

(i) conversão $\left[[\mathrm{X}]_{\mathrm{RadN} / \mathrm{A}}\right]_{\mathrm{RadV}}$ : alegrar, limar, olear...

(ii) sufixação $\left[[\mathrm{X}]_{\mathrm{RadN} / \mathrm{A}} \mathrm{e}\right]_{\mathrm{RadV}}$ : altear, balear, cabecear...

$\left[[\mathrm{X}]_{\mathrm{RadN} / \mathrm{A}} \text { ej }\right]_{\mathrm{Radv}}$ : calejar, pestanejar, praguejar...

$\left[[\mathrm{X}]_{\mathrm{RadN} / \mathrm{A}} \mathrm{iz}\right]_{\mathrm{RadV}}$ : amenizar, canalizar, oficializar...

$\left[[\mathrm{X}]_{\mathrm{RadN} / \mathrm{A}} \text { ific }\right]_{\mathrm{RadV}}$ : clarificar, gelificar, frutificar...

$\left[[\mathrm{X}]_{\mathrm{RadN} / \mathrm{A}} \mathrm{it}\right]_{\mathrm{RadV}}$ : capacitar, debilitar, facilitar...

$\left[[\mathrm{X}]_{\mathrm{RadN} / \mathrm{A}} \mathrm{ic}\right]_{\mathrm{Radv}}$ : duplicar, triplicar, multiplicar... 
$\left[[\mathrm{X}]_{\mathrm{RadN} / \mathrm{A}} \mathrm{e}(\mathrm{s}) \mathrm{c}\right]_{\mathrm{RadV}}$ : alvorecer, escurecer, florescer...

(iii) prefixação $\left[\mathrm{a}[\mathrm{X}]_{\mathrm{RadN} / \mathrm{A}}\right]_{\mathrm{RadV}}$ : acalmar, afivelar, atapetar...

[en $\left.[\mathrm{X}]_{\mathrm{RadN} / \mathrm{A}}\right]_{\mathrm{Radv}}$ : empalhar, engraxar, ensacar...

[es $\left.[\mathrm{X}]_{\mathrm{RadN} / \mathrm{A}}\right]_{\mathrm{Radv}}$ : escavacar, esfriar, esboroar...

(iv) circunfixação $\left[\mathrm{a}[\mathrm{X}]_{\mathrm{RadN} / \mathrm{A}} \mathrm{ec}\right]_{\mathrm{Radv}}$ : amadurecer, apodrecer, anoitecer...

[en $\left.[\mathrm{X}]_{\mathrm{RadN} / \mathrm{A}} \mathrm{ec}\right]_{\mathrm{Radv}}$ : emagrecer, empobrecer, enegrecer...

[es $\left.[\mathrm{X}]_{\mathrm{RadN} / \mathrm{A}} \mathrm{ec}\right]_{\mathrm{Radv}}$ : esclarecer, esvanecer...

[a $\left.[\mathrm{X}]_{\mathrm{RadN} / \mathrm{A}} \mathrm{e}\right]_{\mathrm{RadV}}$ : acobrear, afoguear...

[en $\left.[\mathrm{X}]_{\mathrm{RadN} / \mathrm{A}} \mathrm{e}\right]_{\mathrm{Radv}}$ : emastrear, enlamear...

[es $[\mathrm{X}]_{\mathrm{RadN} / \mathrm{A}}$ e $]_{\mathrm{Radv}}$ : esbofetear, esfaquear, espernear...

[a $[\mathrm{X}]_{\mathrm{RadN} / \mathrm{A}}$ ej $]_{\mathrm{Radv}}$ : aboquejar, apedrejar...

[en $[\mathrm{X}]_{\mathrm{RadN} / \mathrm{A}}$ ej $]_{\mathrm{Radv}}$ : enchamejar, enverdejar...

[es $[\mathrm{X}]_{\mathrm{RadN} / \mathrm{A}}$ ej $]_{\mathrm{Radv}}$ : esbracejar, espanejar, esquartejar...

$\left[\mathrm{a}[\mathrm{X}]_{\mathrm{RadN} / \mathrm{A}} \text { ent }\right]_{\mathrm{RadV}}$ : aformosentar, apodrentar...

[en $[\mathrm{X}]_{\mathrm{RadN} / \mathrm{A}}$ ent $]_{\mathrm{RadV}}$ : endurentar, envelhentar...

[a $\left.[\mathrm{X}]_{\mathrm{RadN} / \mathrm{A}} \mathrm{iz}\right]_{\mathrm{Radv}}$ : aterrorizar, atemorizar...

[en $\left.[\mathrm{X}]_{\mathrm{RadN} / \mathrm{A}} \mathrm{iz}\right]_{\mathrm{Radv}}$ : efeminizar, encolerizar, entronizar...

[es $\left.[\mathrm{X}]_{\mathrm{RadN} / \mathrm{A}} \mathrm{iz}\right]_{\mathrm{Radv}}$ : esfossilizar

Os processos e afixos derivacionais podem diferir entre si por selecionarem bases com propriedades morfofonológicas ou semânticas distintas, ou por exibirem valores semântico-aspetuais mais ou menos subtis, significados sociodialetais e/ou usos discursivo-pragmáticos próprios, que delimitam o seu domínio de aplicação em relação a processos concorrentes ou rivais. Não obstante, a capacidade de prever a utilização de um determinado processo derivacional é muito reduzida. Isso acontece, por exemplo, em casos muito específicos em que existe uma relação preferencial entre determinadas classes de bases complexas e alguns sufixos verbalizadores. Na maioria dos casos, a previsibilidade parece não ser possível em virtude do facto de os processos verbalizadores admitirem distribuições equivalentes e sobrepostas. 
A cofuncionalidade e a polifuncionalidade dos afixos e/ou dos processos derivacionais são situações comuns na formação de verbos heterocategoriais e na formação de palavras em geral. Em primeiro lugar, é frequente que ao serviço dos paradigmas de formação de palavras existam vários processos e afixos derivacionais. Isso é evidente, por exemplo, na formação de verbos deadjetivais de significado resultativo (e.g. sujar, aclarar, clarificar, empobrecer, encurtar, escurecer, esvaziar, suavizar). Longe de representar uma sobrecarga, esta situação constitui uma enorme virtualidade do sistema derivacional. A existência de diversos processos cofuncionais permite não só ultrapassar as constrições impostas pelas bases lexicais, mas também evitar a homonímia na formação de palavras com semânticas e/ou referentes distintos (panar/panificar; traçar/ tracejar; ensanguentar/ sanguificar; greguejar/grecizar; empedrar/ petrificar/apedrejar). O que se verifica frequentemente é que as palavras construídas sobre uma mesma base através de processos/afixos concorrentes se especializam do ponto de vista semântico-referencial.

Em segundo lugar, verbos formados através de um determinado processo derivacional podem exibir significados muito diversificados. Nestes casos, a diversidade semântica dos verbos decorre da conjugação do significado nuclear de cada processo/afixo e do significado denotado pelas bases. Assim, em função da semântica típica das bases, produzem-se verbos com um significado resultativo (atemorizar, aveludar, emagrecer, falsificar), ornativo (engraxar, aromatizar), locativo (aprisionar, crucificar, empacotar), instrumental (apunhalar, chicotear), performativo (boicotar, cortejar, enferrujar) ou modal (arbitrar, profetizar, pavonear).

Os verbos denominais e deadjetivais caraterizam-se, na sua globalidade, por uma mudança de estado-de-coisas que pode envolver o incremento ou transferência de propriedades, estados ou entidades. Essa mudança de estado-de-coisas pode ser concebida e/ou expressa como interna ou externamente causada, sendo neste último caso manifesta a intervenção de um sujeito causativo. 
As constrições combinatórias e as propriedades individuais dos processos em questão ajudam a explicar a complementaridade e/ou competição entre os diversos processos derivacionais na formação de verbos em português. Apesar das especificidades que caraterizam cada um dos processos verbalizadores, existem alguns domínios de aplicação em que estes são concorrentes e rivais, sendo a sua ativação determinada por fatores diversos, nem sempre de natureza linguística (frequência de uso, moda, tipo de discurso, etc.). $\mathrm{Na}$ seleção de bases complexas há algumas solidariedades entre afixos e algumas condições preferenciais de ocorrência por parte de alguns processos/afixos verbalizadores. Todavia, quando as bases são simples, não parece haver nenhuma propriedade da base que determine a ativação de um determinado processo de formação de verbos. Por este motivo, existem séries de verbos corradicais, formados sobre o mesmo radical de base mas com processos derivacionais diferentes (aclarar, clarear, clarificar, esclarecer). Estas bases são, pois, um domínio em que os diversos processos/ afixos competem entre si, sendo ativados em função do seu papel diferenciador, que se manifesta de forma mais ou menos sistemática.

A maioria dos verbos deadjetivais e denominais descreve a afetação de uma entidade, adquirindo ou passando a possuir uma qualidade, propriedade ou estado. Em muitos casos, ao semantismo de 'mudança de estado-de-coisas' acresce o valor 'causativo', que implica a expressão da causa (agentiva ou não) que induz a mudança sofrida pelo objeto. Note-se, no entanto, que a expressão da causa é muitas vezes opcional, podendo os verbos derivados expressar alternativamente eventos não causativos. Esse fenómeno é tradicionalmente conhecido no domínio da semântica e da sintaxe como "alternância causativo/incoativo" ou simplesmente como "alternância causativa».

Em função do tipo de bases a que se ligam, os processos derivacionais produzem verbos com valores semânticos diversos (causativos 
e não causativos; télicos e atélicos). Por exemplo, no que aos verbos deadjetivais diz respeito, a distinção entre as transições graduais e as transições simples está relacionada com a natureza (im)perfetiva e graduável ou não da propriedade denotada pela base adjetival. Os verbos derivados de adjetivos graduáveis comportam-se geralmente como transições graduais, sendo parafraseáveis 'tornar/ ficar mais Ab' (cf. avermelhar, aclarar, alargar, encurtar, entortar, esfriar, esquentar), enquanto os verbos derivados de adjetivos não graduáveis denotam tipicamente transições simples, sendo parafraseáveis por 'tornar/ficar Ab' (cf. anular, enviuvar).

Embora haja diversos casos de coincidência de significado e/ ou de sobreposição semântica entre diferentes processos/afixos verbalizadores, o uso dos vários processos de formação de verbos difere no que diz respeito à sua diversidade semântica dos produtos derivacionalmente construídos. Se é verdade que todos os processos permitem formar verbos resultativos, nem todos formam verbos locativos ou ornativos, e apenas alguns formam verbos instrumentais, performativos ou modais. No Quadro IV.12 distribuem-se os processos derivacionais em função da sua capacidade de produção de verbos de distintas classes semânticas.

\begin{tabular}{|c|c|c|c|c|c|}
\hline 6 classes & 5 classes & 4 classes & 3 classes & 2 classes & 1 classe \\
\hline $\begin{array}{c}\text { resultativo } \\
\text { performativo } \\
\text { instrumental } \\
\text { locativo } \\
\text { ornativo } \\
\text { modal }\end{array}$ & $\begin{array}{c}\text { resultativo } \\
\text { performativo } \\
\text { instrumental } \\
\text { locativo } \\
\text { ornativo } \\
\text { - }\end{array}$ & $\begin{array}{c}\text { resultativo } \\
\text { performativo } \\
- \\
\text { locativo } \\
\text { ornativo } \\
-\end{array}$ & 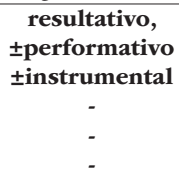 & $\begin{array}{c}\text { resultativo, } \\
\text { performativo } \\
- \\
- \\
- \\
-\end{array}$ & $\begin{array}{c}\text { resultativo } \\
- \\
- \\
- \\
- \\
\text { - }\end{array}$ \\
\hline $\begin{array}{c}\text {.conversão. } \\
a- \\
e n- \\
e s- \\
-e- \\
-e j-\end{array}$ & \multirow[t]{2}{*}{$\begin{array}{l}a-\ldots-e- \\
a-\ldots-e j-\end{array}$} & \multirow[t]{2}{*}{$-i f i c-$} & $\begin{array}{c}\text { [-perf,-instr]: } \\
\text { en-...-e- } \\
\text { [+perf,-instr]: } \\
\text { en-...-ej- }\end{array}$ & \multirow[t]{2}{*}{$\begin{array}{c}-e(s) c- \\
a-\ldots-e(s) c- \\
e n-\ldots-e(s) c-\end{array}$} & \multirow{2}{*}{$\begin{array}{c}-i t- \\
-i c- \\
e s-\ldots-e(s) c- \\
a-\ldots-e n t- \\
e n-\ldots-e n t- \\
a-\ldots-i z- \\
e n-\ldots-i z- \\
e s-\ldots-i z-\end{array}$} \\
\hline $\begin{array}{c}-l z- \\
e s-\ldots-e-\end{array}$ & & & $\begin{array}{c}{[+ \text { perf, }+ \text { instr] }]} \\
\text { es-...-ej- }\end{array}$ & & \\
\hline
\end{tabular}

Quadro IV.12. Número de classes semânticas de verbos produzidas por cada um dos processos derivacionais 
Como se pode avaliar a partir deste Quadro, os domínios semânticos de aplicação dos diferentes processos derivacionais estão longe de ser idênticos e coincidentes. A conversão, a sufixação com - $e-$, $-e j-$ e -iz-, a prefixação $\operatorname{com} a-$, $e n-$ e $e s-$, e a circunfixação de es-...-e-são os processos semanticamente mais diversificados, produzindo verbos que integram as seis classes semânticas apresentadas. No polo oposto estão a sufixação em -it- e -ic- e a circunfixação em $a-\ldots-i z-$, en-...-iz-, es-...-iz-, $a$ ...-ent-, en-...-ent- e em es-...ee(s)c-, processos que apresentam um domínio de aplicação mais restrito, apenas formando verbos resultativos.

O valor menos representado é o modal, seguindo-se-lhe o instrumental, e depois os locativo, ornativo e performativo.

Os dados deste quadro permitem visualizar que a sufixação só em parte é funcionalmente equivalente à que envolve a circunfixação : a-...-iz-, en-...-iz- e es-...-iz-apenas têm valor resultativo, mas o sufixo -iz-admite todos os valores semânticos. De igual modo, -e-, $e s-\ldots-e-\mathrm{e}-e j$ - codificam todos os valores semânticos, mas $a-\ldots-e-\mathrm{e}$ $a-\ldots-e j$ - não veiculam valor modal; en-...e-é é marcado pelos traços [+result, -perf, -instr], enquanto en-...-ej- se caracteriza pelos traços [+result, +perf, -instr] e es-...-ej- pelos traços [+result, +perf, +instr].

No que à circunfixação diz respeito, apenas es-...-e-, $a-\ldots-e-\mathrm{e}$ $a$-...-ej- são versáteis (cf. Quadro IV.12), em consonância com o facto de serem dos mais produtivos. Os esquemas que envolvem $-e(s) c$-, e que correspondem a quase metade $(48,77 \%)$ dos que envolvem circunfixação, são dos menos versáteis, em conformidade com o funcionamento do sufixo $-e(s) c$-, não obstante ser o que mais se acopla a adjetivos (cf. 4.3.2.3.3). Os demais esquemas de circunfixação são residuais.

A conversão é de todos os processos o mais versátil, talvez precisamente por não envolver o recurso a um afixo. 


\subsection{Formação isocategorial de verbos}

Nesta secção analisam-se os processos de formação de verbos a partir de outros verbos já existentes na língua. Neste caso, a língua tem ao seu dispor exclusivamente processos afixais: prefixação ou sufixação.

\subsubsection{Verbos deverbais sufixados}

Os sufixos que intervêm na formação de verbos deverbais não são diferentes dos que atuam na formação de nomes ou adjetivos isocategoriais (cf. cap. 5). No quadro que se segue indicam-se alguns dos sufixos mais usados na formação de verbos deverbais.

\begin{tabular}{|l|l|}
\hline \multicolumn{1}{|c|}{ Sufixos } & \multicolumn{1}{c|}{ Verbos deverbais } \\
\hline- ic- & tossicar, bebericar, depenicar \\
\hline -ilh- & fervilhar \\
\hline- inh- & cuspinhar, escrevinhar \\
\hline- isc- & mordiscar, lambiscar \\
\hline$-\boldsymbol{i t}-$ & saltitar, dormitar \\
\hline- ol- & cantarolar \\
\hline
\end{tabular}

Quadro IV.13. Sufixos deverbais formadores de verbos isocategoriais

Estes sufixos caraterizam-se pelo facto de serem policategoriais, pois combinam-se com bases de várias categorias gramaticais, não apenas verbais, mas também nominais e adjetivais; são também isocategoriais, pois a palavra derivada manifesta a mesma categoria da da base (cf. saltar $_{\mathrm{V}}>\operatorname{salt}[$ it $]$ ar $_{\mathrm{V}} ;$ burro $_{\mathrm{N}}>$ burr $[i t] o_{\mathrm{N}} ;$ pequeno $_{\mathrm{A}}>$ pequen $\left.[i t] o_{\mathrm{A}}\right)$.

Quanto ao seu significado, a maioria desses sufixos expressa um significado de caráter avaliativo, mais especificamente de baixa intensividade, a que se associa, por vezes, o aspeto iterativo, sem alterar contudo o significado da base lexical a que se juntam. Assim, expressam em geral uma 'ação pouco intensa' (lambiscar, 
mordiscar) e/ou uma 'ação repetida' (bebericar, cantarolar, saltitar). Celso Cunha e Lindley Cintra (1984) atribuem a estes verbos um valor 'frequentativo-diminutivo', a que acresce, no caso dos verbos em -inh- (cuspinhar, escrevinhar) o valor 'pejorativo'.

\subsubsection{Verbos deverbais prefixados}

Mais significativos, porque mais numerosos, são os prefixos verbalizadores deverbais. Tal como sucede na sufixação isocategorial, estes prefixos podem acoplar-se a bases de várias categorias sintáticas (verbos, nomes, adjetivos), formando palavras com a mesma categoria.

No quadro que se segue indicam-se alguns dos prefixos usados na formação de verbos deverbais e os respetivos valores semânticos.

\begin{tabular}{|c|c|c|c|}
\hline \multicolumn{2}{|c|}{ Classes semânticas } & Prefixos & Verbos deverbais \\
\hline \multirow{11}{*}{\multicolumn{2}{|c|}{ a. Localização }} & ante- & antepor, antedatar, antever \\
\hline & & circum- / circun- & circum-navegar, circunscrever \\
\hline & & entre-/inter- & entrecortar, entremear, interpor \\
\hline & & $e x-/ e s-/ e-$ & exportar, escorrer, emigrar \\
\hline & & $i n-/ i m-/ i-$ & inscrever, importar, imigrar \\
\hline & & pós-/pos- & pós-datar, pospor \\
\hline & & pré-/pre- & pré-estabelecer, prever \\
\hline & & sobre- & sobrepor \\
\hline & & sub-/sob-/so- & subarrendar, sobestar, soterrar \\
\hline & & trans-/tres- & transpor, trespassar \\
\hline & & ultra- & ultrapassar \\
\hline \multirow{2}{*}{ b. Negação } & oposição & contra- & contradizer, contrapor \\
\hline & reversão & des- & desdizer, desfazer, desmontar \\
\hline \multirow{7}{*}{ c. Modificação } & \multirow{3}{*}{ intensificação } & super-/sobre- & superabundar, sobrevalorizar \\
\hline & & sub- & subestimar, subvalorizar \\
\hline & & biper- & hiperproteger, hiperindustrializar \\
\hline & \multirow{4}{*}{ quantificação } & bi- & bipartir, bissegmentar \\
\hline & & entre- & entreabrir \\
\hline & & equi- & equivaler, equidistar \\
\hline & & semi- & semicerrar \\
\hline \multicolumn{2}{|l|}{ d. Conjunção } & co-/con-/com- & cooperar; concorrer, compartilhar \\
\hline
\end{tabular}




\begin{tabular}{|l|l|l|}
\hline e. Reciprocidade & inter-/entre- & intercomunicar, entreolhar-se \\
\hline f. Reflexividade & auto- & autodestruir-se, autodenominar-se \\
\hline g. Repetição / iteração & re- & recolocar, refazer, reescrever \\
\hline
\end{tabular}

Quadro IV.14. Significados dos prefixos deverbais

\subsubsection{Significado dos prefixos}

Como se observa no quadro anterior, quanto ao seu significado, estes prefixos inscrevem-se em várias classes semânticas. Ademais, em muitos casos, alguns destes prefixos expressam outros valores semânticos (cf. cap. 7). Por exemplo, o prefixo des- pode expressar 'localização', 'contrariedade', 'privação' e 'reversão'. Por outro lado, um mesmo conteúdo semântico pode ser expresso através de prefixos distintos. A ideia de 'movimento para dentro' encontra-se, por exemplo, em verbos prefixados quer com in- (importar, imigrar) quer com intro- (introduzir, intrometer).

Em geral, os valores semânticos de um prefixo procedem de um único conteúdo significativo, geralmente um valor de localização, aplicável num eixo espacial e/ou num eixo temporal (sobrepor), passando depois da ideia de extensão e de limite espacial à de grau de intensidade (sobrecarregar). Do valor locativo de 'separação, procedência' (descarrilar) terão derivado os sentidos de 'privação' (descamisar, descascar), de 'reversão' (desfazer, desligar) e de 'negação' (desobedecer).

\subsection{Localização}

O grupo mais numeroso de prefixos que formam verbos deverbais é composto por unidades que indicam algum tipo de localização (por vezes decorrente de movimento) ou relação espacial ou temporal. A localização manifesta-se por significados muito diversos, 
que apresentamos a partir do esquema elaborado por Celso Cunha e Lindley Cintra (1984):

\begin{tabular}{|c|c|c|}
\hline Prefixo & Sentido & Exemplificação \\
\hline$a b-$ & afastamento, separação & abduzir, abjungir, abjurar \\
\hline$a(d)-$ & aproximação, direção & advir, adscrever, afluir \\
\hline ante- & anterioridade & antepor, antedatar, antever \\
\hline circum-/circun- & movimento em torno & circum-navegar, circunscrever \\
\hline de- & movimento de cima para baixo & decair, decrescer \\
\hline des- & separação, ação contrária & descolar, desligar \\
\hline$d i(s)-$ & $\begin{array}{l}\text { separação, movimento para } \\
\text { diversos lados }\end{array}$ & dissociar, difamar \\
\hline$e x-/ e s-/ e-$ & movimento para fora & exportar, escorrer, emigrar \\
\hline extra- & movimento para fora & extraviar, extravasar \\
\hline in- & movimento para dentro & ingerir, importar, imigrar \\
\hline inter-/entre- & posição no meio de & interpor, entrelaçar, entrecortar \\
\hline intro- & movimento para dentro & intrometer, introverter \\
\hline justa- & posição ao lado & justapor \\
\hline per- & movimento através & percorrer, perfurar, pernoitar \\
\hline pós-/pos- & posterioridade & pós-datar, pospor \\
\hline pré-/pre- & anterioridade & pré-ajustar, preconceber, prever \\
\hline pro- & movimento para a frente & propor, prosseguir, promover \\
\hline re- & movimento para trás & refluir, repatriar \\
\hline retro- & movimento mais para trás & retroceder, retroagir \\
\hline $\begin{array}{l}\text { sub-/su(s)- } \\
\text { sob-/so- }\end{array}$ & posição em baixo & $\begin{array}{l}\text { subjugar }, \text { suster }, \text { supor } \\
\text { sobestar }, \text { soterrar }\end{array}$ \\
\hline super-/sobre- & posição em cima & supervisionar, sobrepor \\
\hline trans-/tres- & movimento para além de & transpor, transcrever, trespassar \\
\hline ultra- & posição além do limite & ultrapassar, ultracentrifugar \\
\hline
\end{tabular}

Quadro IV.15. Significados locativos dos prefixos deverbais (adaptado de Cunha \& Cintra 1984)

\subsection{Negação}

Alguns prefixos negam algum traço semântico do conteúdo da base, pelo que o significado da forma prefixada é oposto ou contrário ao expresso pela base verbal.

O prefixo contra- manifesta um significado de 'oposição', uma vez que os verbos portadores deste prefixo denotam uma ação 
que anula os resultados alcançados com a ação indicada na base (contra-atacar, contradizer, contraindicar).

Negativo é também o valor dos prefixos in-(indeferir) e des(desagradar, desaproveitar, desconfiar, desobedecer), visto que o verbo derivado denota uma ação contrária à da base. Do significado de 'afastamento' é frequente o desenvolvimento de significados negativos de 'ação contrária' e de 'reversão' (descoser, desligar, desmontar). O conceito de reversão faz referência à realização de uma ação de retorno a um estado prévio, de onde parte a ação não reversiva (ligar/desligar; aparafusar/desaparafusar).

\subsection{Modificação}

Sob esta denominação, faz-se referência a processos que introduzem alguma 'modificação' no conteúdo semântico da base lexical a que se juntam, sem alterar de modo fundamental o seu significado.

Alguns prefixos expressam um significado de tipo avaliativo, aportando ao conteúdo significativo de uma palavra uma intensificação aumentativa ('muito', 'excesso') ou diminutiva ('pouco') (cf. cap. 7: 7.8). É o que acontece com os prefixos hiper- (hiperproteger), super(superexcitar, superlotar), sobre- e sub- (sobrevalorizar, subvalorizar).

Um segundo grupo de prefixos institui quantificação, indicando seja a de um número exato ([bi]partir, [tri]partir), seja a de uma quantidade imprecisa que modifica o conteúdo semântico do verbo-base, como em [entre]abrir, [equi]valer, [semi]cerrar (cf. cap. 7: 7.10).

\subsection{Conjunção}

O prefixo $c o(n)$-, que ocorre sob diferentes variantes em diferentes contextos fonológicos (cf. cap. 7: 7.5), forma verbos que assinalam 
uma ação conjunta levada a cabo por dois ou mais sujeitos (concelebrar, conviver, coabitar, coexistir, cooperar). Às vezes, acumulam sentido recíproco (coligar-se).

\subsection{Reciprocidade}

As formas prefixais entre- e inter- (cf. cap. 7: 7.13) desenvolvem, a partir do significado locativo de 'posição no meio de', o significado de 'ação que se manifesta de forma recíproca' entre duas entidades (entrechocar, intercambiar). Este valor semântico é frequente em verbos prefixados com entre- e inter-reforçados pelo clítico se (Ribeiro 2011) que expressa a reciprocidade entre duas entidades (entrecruzar-se, entreolhar-se, interconectar-se, inter-relacionar-se).

\subsection{Reflexividade}

A reflexividade (cf. cap. 7: 7.12) supõe a identificação de dois argumentos: o sujeito e o objeto direto. O prefixo auto-, reforçado pelo pronome $s e$, denota uma ação executada e sofrida pela mesma entidade (autoabastecer-se, autoinjetar-se, autopromover-se, autopropor-se).

\subsection{Repetição / iteração}

Os verbos prefixados com re- expressam tipicamente ações que se repetem (cf. cap. 7: 7.3), como reagrupar, reaparecer, reconquistar, redecorar, refazer, reordenar. Este processo de prefixação, ao indicar a repetição numa segunda vez, modifica aspetualmente a ação denotada pela base verbal. 